\title{
Synoptic-Scale Zonal Available Potential Energy Increases in the Northern Hemisphere
}

\author{
Kevin A. Bowley, ${ }^{\text {a }}$ Eyad H. Atallah, and John R. Gyakum \\ Department of Atmospheric and Oceanic Sciences, McGill University, Montreal, Quebec, Canada
}

(Manuscript received 3 October 2017, in final form 7 April 2018)

\begin{abstract}
Available potential energy (APE), a measure of the energy available for conversion to kinetic energy, has been previously applied to examine changes in baroclinic instability and seasonal changes in the general circulation. Here, pathways in which the troposphere can build the reservoir of zonal available potential energy $A_{Z}$ on synoptic (3-10 day) time scales are explored. A climatology of $A_{Z}$ and its generation $G_{Z}$ and conversion terms are calculated from the National Centers for Environmental Prediction-Department of Energy Reanalysis 2 dataset from 1979 to 2011 for $20^{\circ}-85^{\circ} \mathrm{N}$. A standardized anomaly-based identification technique identifies $183 A_{Z}$ buildup events, which are grouped into two event types based upon their final $A_{Z}$ standardized anomaly $(\sigma)$ value: 1 ) buildup anomalous (BA) events, which exceed $1.5 \sigma$, and 2) buildup neutral (BN) events, which do not exceed 1.5 $\sigma$. Increases in $G_{Z}$ and reductions in baroclinic conversion $C_{A}$, source and sink terms for $A_{Z}$, are shown to equally contribute toward increasing $A_{Z}$ in most seasons. A synoptic analysis of composited mass fields for winter BA events $(n=18$ events $)$ and winter BN events $(n=28$ events) is performed to identify contributions to anomalously low $C_{A}$ and high $G_{Z}$. A process of high-latitude cooling near $160^{\circ} \mathrm{E}-120^{\circ} \mathrm{W}$ is found for both composite event types. The cooling processes are characterized by a period of poleward moisture flux and ascent followed by an isolation of the Arctic from the midlatitude flow, resulting in enhanced $G_{Z}$. Negative anomalies in $C_{A}$ are also diagnosed, which generally occur in regions with northerly dynamic tropopause wind anomalies and neutral to positive thickness anomalies.
\end{abstract}

\section{Introduction}

Zonal available potential energy (APE), $A_{Z}$, has been shown to be a robust tool for interpreting changes to the general circulation of the troposphere on synoptic to annual time scales (e.g., Lorenz 1955, 1960; Dutton and Johnson 1967; Johnson 1967; Wintels and Gyakum 2000). It is a measure of the potential energy in a domain available for conversion to eddy available potential energy $A_{E}$ and eddy kinetic energy $(\mathrm{KE}), K_{E}$. The generation of $A_{Z}$ occurs through enhancements in the magnitude of the meridional temperature gradient by diabatic processes (e.g., Romanski and Rossow 2013). Depletions of $A_{Z}$ can occur through a conversion to zonal kinetic energy $K_{Z}$ (e.g., Peixóto and Oort 1974), but it is more robustly and rapidly depleted through baroclinic conversions to $A_{E}$ and $K_{E}$ during periods

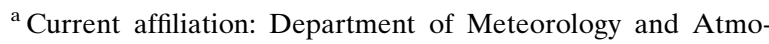
spheric Science, The Pennsylvania State University, University Park, Pennsylvania.
}

Corresponding author: Kevin A. Bowley, kbowley@psu.edu of strong synoptic-scale eddies (e.g., Lorenz 1955; Johnson 1970; Peixóto and Oort 1974; Bosart et al. 1996; Veiga et al. 2008; Pezza et al. 2010). Previous studies have proposed mechanisms to describe both the annual cycle in $A_{Z}$ (e.g., Lorenz 1955; Brown 1964; Oort 1964; Dutton and Johnson 1967; Peixóto and Oort 1974; Wintels and Gyakum 2000) as well as short-term (synoptic time scales) depletions (e.g., Dutton and Johnson 1967; Wiin-Nielsen and Brown 1962; Brown 1964; Lin and Smith 1979; Lau and Lau 1984; Bosart et al. 1996; Wintels and Gyakum 2000; Pezza et al. 2010). However, little attention has been placed on APE increases through midlatitude processes occurring on synoptic time scales. The goal of this paper is to improve this area of understanding.

The Lorenz energy cycle (Fig. 1), used to describe the pathway of energy transfer in the atmosphere, is composed of a series of energy storage, generation, conversion, and boundary terms that were first formalized by Lorenz (1955). Variability in $A_{Z}$ is a function of $A_{Z}$ generation $\left(G_{Z}\right)$ and conversions of $A_{Z}$ to $A_{E}\left(C_{A}\right)$ and $K_{Z}\left(C_{Z}\right)$ (e.g., Lorenz 1955; Oort and Peixóto 1974; Veiga et al. 2008; Pezza et al. 2010). Differential heating 


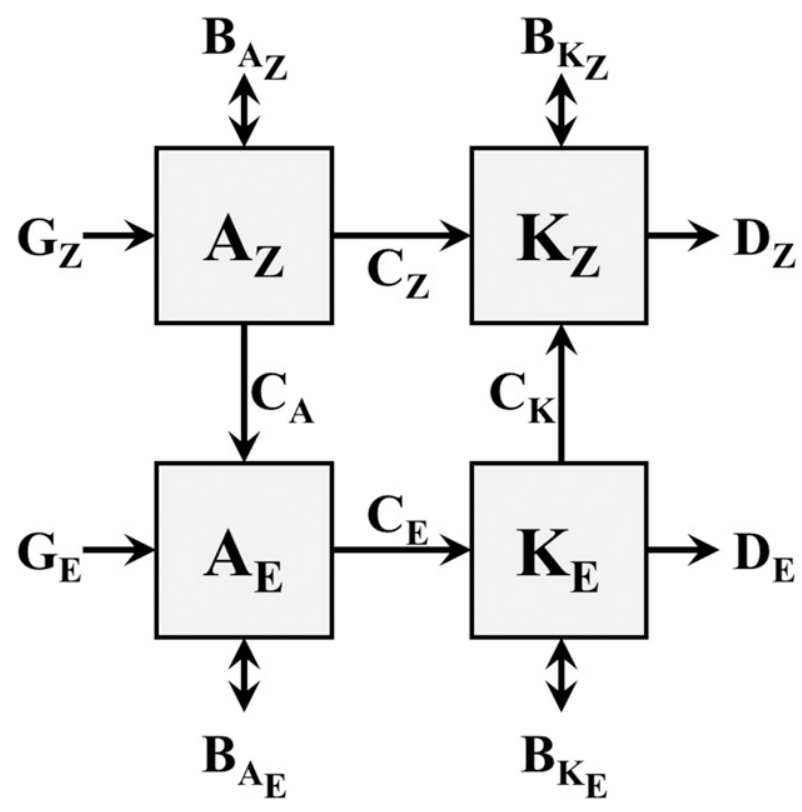

FIG. 1. Box diagram of the Lorenz energy cycle. Generation terms $G$, depletion terms $D$, and boundary residual terms $B$ are sources and sinks for the system, while conversions $C$ convert energy between $\operatorname{APE}\left(A_{Z}, A_{E}\right)$ and $\operatorname{KE}\left(K_{E}, K_{Z}\right)$. Arrows point in the most common direction of energy transfer $(C)$ and input/output $(G, D, B)$. Adapted from Oort and Peixóto (1974).

associated with diabatic heating, resulting in increased meridional thermal gradients, leads to positive $G_{Z}$ and increased baroclinic instability (e.g., Winston and Krueger 1961; Romanski and Rossow 2013). Baroclinic conversion of $A_{Z}$ to $A_{E}\left(C_{A}\right)$ is achieved through thermally direct circulations that act to break down strong baroclinic zones while strengthening eddy circulations (e.g., Lorenz 1955; Winston and Krueger 1961). Boundary terms can be of importance in limited domain studies of $A_{Z}$ but are of little importance for hemispheric domains.

We can physically interpret $A_{Z}$ is through the magnitude of meridional temperature gradients and the static stability of the atmosphere. Periods of strong meridional planetary baroclinicity are associated with high values of $A_{Z}$, reflecting the strength of upper-tropospheric zonal winds through thermal wind arguments. As such, either zonal term in the Lorenz energy cycle $\left(A_{Z}\right.$ and $\left.K_{Z}\right)$ represents an appropriate diagnostic for the overall strength of the general circulation. The Northern Hemisphere $(\mathrm{NH})$ budget for $A_{Z}$ is strongly driven by changes in meridional baroclinicity, owing to the annual cycle in differential radiative heating. Maximum values of $A_{Z}$ occur in winter months, decrease to a climatological minimum in summer, and increase in the fall months in association with the acceleration of the NH zonal jet (e.g., Peixóto and Oort 1974; Oort and Peixóto 1974; Cordeira 2011). Changes in static stability, though important, have a lesser impact on the budgets of
$A_{Z}$ and $A_{E}$ (e.g., Dutton and Johnson 1967; Duck Min and Horn 1982). Subseasonal (10-50 day) variations in $A_{Z}$ account for a much smaller percentage (3.2\%) of the total variability (Wintels and Gyakum 2000). However, robust synoptic-time-scale variability of $A_{Z}$ has been shown to be associated with variations to the synopticscale flow patterns that are associated with large sensible weather impacts (e.g., Bosart et al. 1996; Wintels and Gyakum 2000) and are of primary interest to this study.

Synoptic-time-scale fluctuations in $A_{Z}$ have been attributed to a number of atmospheric phenomena and their associated synoptic- to planetary-scale flow reconfigurations. Variations in the structures and orientations of diabatic heating can result in changes to $G_{Z}$, which act to increase or decrease $A_{Z}$ (e.g., Clapp 1961; Winston and Krueger 1961; Wiin-Nielsen and Brown 1962; Krueger et al. 1965; Chen 1982; Hansen and Nagle 1984; Romanski and Rossow 2013). Pezza et al. (2010) found that the enhancement of meridional temperature gradients in association with a warm-core subtropical high and highlatitude cooling in the North Pacific resulted in an increase in regional baroclinicity and $A_{Z}$. Such an increase in regional baroclinicity can be manifest as an elongation of the North Pacific jet, which has been shown to be associated with anomalously high periods of $A_{Z}$ (Cordeira 2011). High-latitude surface sensible heat flux from the atmosphere to the ground, resulting in atmospheric cooling, is found to be the largest contributor to $A_{Z}$ generation in winter months, while upper-tropospheric latent heat release in the tropics is the dominant source of generation in summer months (Romanski and Rossow 2013).

Synoptic-scale cyclonic eddies can act to both increase and decrease $A_{Z}$. Diabatic processes from clouds and precipitation associated with cyclonic eddies have been shown to increase APE generation when acting to strengthen temperature gradients (e.g., Winston and Krueger 1961; Wiin-Nielsen and Brown 1962; Brown 1964; Smith and Dare 1986). However, such eddies have also been shown to deplete $A_{Z}$ through wave amplifications, which can induce strong meridional flow and increased baroclinic conversion (e.g., Smith and Dare 1986; Bosart et al. 1996; Veiga et al. 2008; Pezza et al. 2010). Robust increases in baroclinic conversions are found to be associated with the robust meridional heat transport associated with explosively deepening cyclones, while weaker cyclones do not exhibit a strong reduction in $A_{Z}$ (Black and Pezza 2013).

Equatorward displacements of cold air masses over North America and East Asia (e.g., cold-air outbreaks) have been associated with depletions of $A_{Z}$ (Lau and Lau 1984; Wintels and Gyakum 2000; Garreaud 2001; Cordeira 2011), but few studies have examined the impact of the generation of these air masses on changes in 
$A_{Z}$. On seasonal and subseasonal time scales, Cordeira (2011) found that $A_{Z}$ increases from phase 3 to phase 4 of the Madden-Julian oscillation and decreases from phase 6 to phase 7. Cordeira (2011) also found that $A_{Z}$ increases from an anomalously low to anomalously high state over a 90-day period when anomalously high Niño3.4 sea surface temperatures were observed. A similarly long increase in $A_{Z}$ from an anomalously low state to the mean state was also found during a period of increasingly negative anomalies in Niño-3.4 sea surface temperatures (Cordeira 2011).

Buildups in $A_{Z}$ have been broadly described as a seasonal process, despite evidence that synoptic (3-10 day)time-scale dynamics play an important role in $A_{Z}$ modulation (Wintels and Gyakum 2000; Cordeira 2011). Therefore, the purpose of this study is to examine the processes that act to increase $A_{Z}$ on synoptic time scales. To do so, a framework is established to identify synoptictime-scale $A_{Z}$ buildup events across all meteorological seasons and is presented in section 2 . In section $3 \mathrm{a}$, results from seasonal composites of these events are presented to investigate the energetic pathway associated with rapid increases in $A_{Z}$. In section $3 \mathrm{~b}$, we present a synoptic evolution of composited winter $A_{Z}$ buildup events, with a focus on features that can act to increase $A_{Z}$. Finally, in section 4 , we present a discussion of these synoptic process in light of the Lorenz energy cycle climatological source $\left(G_{Z}\right)$ and sink $\left(C_{A}\right)$ terms for $A_{Z}$ and propose mechanisms by which these features can perturb the hemispheric energetic state.

\section{Methodology}

\section{a. Reanalysis data}

Energetics calculations are performed using the National Centers for Environmental Prediction (NCEP)Department of Energy (DOE) Reanalysis 2 global reanalysis dataset (Kanamitsu et al. 2002). This dataset has a temporal resolution of $6 \mathrm{~h}$, and our period of analysis was 1 January 1979-31 December 2011. This time period was chosen to correspond approximately to the common climate reference period (1980-2010) while also sampling from the beginning of the satellite era in the reanalysis (1979). The horizontal resolution is $2.5^{\circ} \times$ $2.5^{\circ}$ with 17 pressure levels ranging from 1000 to $10 \mathrm{hPa}$, though for our purposes, we utilize the 12 lowest vertical layers $(1000-100 \mathrm{hPa})$ and a subdomain of $20^{\circ}-85^{\circ} \mathrm{N}$. The domain was limited in order to isolate midlatitude tropospheric impacts on energetics. O'Gorman (2010) has shown that the southern boundary of $20^{\circ} \mathrm{N}$ is sufficient to capture seasonal shifts in Northern Hemisphere midlatitude storm tracks while also generally preventing the influence of the tropical troposphere on energetic

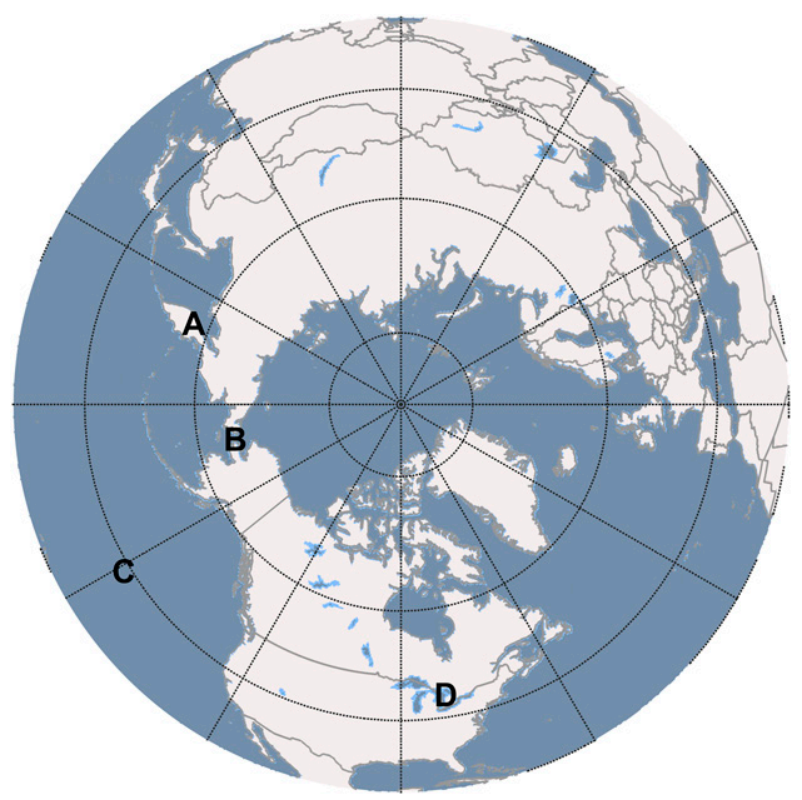

FIG. 2. Reference map of NH analysis domain. Regions of note, in order of increasing longitude from the prime meridian, are Kamchatka Peninsula region (point A), Bering and Chukchi Seas region (point B), eastern Pacific region (point C), and Great Lakes region (point $\mathrm{D})$.

calculations. The domain of analysis, along with notable regions for discussion in the following sections, is shown in Fig. 2.

\section{b. Energetics calculations}

APE has been previously diagnosed in either an exact isentropic coordinate system (e.g., Lorenz 1955; Dutton and Johnson 1967) or an approximate isobaric coordinate system (e.g., Lorenz 1955; Muench 1965; Oort and Peixóto 1974; Peixóto and Oort 1974; Wintels and Gyakum 2000). The majority of studies have applied the latter system, owing to its reduced computational intensity and applicability to a traditional meteorological analysis, and for comparison to previous studies (e.g., Oort 1964; Muench 1965; Peixóto and Oort 1974; Wintels and Gyakum 2000; Pezza et al. 2010). Studies comparing the exact and approximate equations have shown that the approximate equations generally overestimate the value of APE, but the temporal variability of APE is similar between the two frameworks (Dutton and Johnson 1967; Duck Min and Horn 1982). The terms of the Lorenz energy cycle can also be computed using spatial, temporal, or spatial and temporal averages, resulting in a spaceonly, time-only, and space-time analysis of the energetics terms (Oort 1964).

Here, we compute $A_{Z}$ [Eq. (1)] and the associated conversion terms $\left[C_{A}\right.$ in Eq. (2) and $C_{Z}$ in Eq. (3)] in 
isobaric coordinates utilizing the equations of Peixóto and Oort (1974) in a space-only framework (Oort 1964). This choice of framework was made to ensure that the variability associated with synoptic time scales was resolved and not removed through temporal smoothing associated with the space-time approach. An isobaric coordinate system was chosen, as it provided a more simplified conceptual basis for analysis (Lorenz 1955) and resulted in significantly less computation expense. The energetics terms are defined as

$$
\begin{aligned}
A_{Z}= & \frac{1}{2} c_{p} \int_{1000 \mathrm{hPa}}^{100 \mathrm{hPa}} \int_{0^{\circ}}^{360^{\circ}} \int_{20^{\circ} \mathrm{N}}^{85^{\circ} \mathrm{N}} \gamma[T]^{\prime \prime 2} d m \\
C_{A}= & -c_{p} \int_{1000 \mathrm{hPa}}^{100 \mathrm{hPa}} \int_{0^{\circ}}^{360^{\circ}} \int_{20^{\circ} \mathrm{N}}^{85^{\circ} \mathrm{N}} \gamma\left[v^{*} T^{*}\right] \frac{\partial[T]}{a \partial \phi} d m \\
& -c_{p} \int_{1000 \mathrm{hPa}}^{100 \mathrm{hPa}} \int_{0^{\circ}}^{360^{\circ}} \int_{20^{\circ} \mathrm{N}}^{85^{\circ} \mathrm{N}} P^{-\kappa}\left[\omega^{*} T^{*}\right] \frac{\partial\left(\gamma P^{-\kappa}[T]^{\prime \prime}\right)}{\partial P} d m \\
C_{Z}= & -\int_{1000 \mathrm{hPa}}^{100 \mathrm{hPa}} \int_{0^{\circ}}^{360^{\circ}} \int_{20^{\circ} \mathrm{N}}^{85^{\circ} \mathrm{N}}[v] g \frac{\partial[\Phi]}{a \partial \phi} d m \\
G_{Z}= & c_{p} \int_{1000 \mathrm{hPa}}^{100 \mathrm{~Pa}} \int_{0^{\circ}}^{360^{\circ}} \int_{20^{\circ} \mathrm{N}}^{85^{\circ} \mathrm{N}} \gamma[T]^{\prime \prime}[\dot{Q}]^{\prime \prime} d m
\end{aligned}
$$

The terms in Eqs. (1)-(4) are summarized in Table 1. Integrals were performed in the prescribed Northern Hemisphere domain $\left(20^{\circ}-85^{\circ} \mathrm{N}, 1000-100 \mathrm{hPa}\right)$ for each 6-h time interval and smoothed using a 3-day low-pass filter in order to remove any subsynoptic-scale processes (e.g., diurnal variability), resulting in a smoothed daily $\mathrm{NH}$ energy budget. The removal of below-ground data points was shown by Marques et al. (2009) to improve the accuracy of the approximate equations by up to $10 \%$ relative to the exact equations; therefore, we apply a surface mask $\beta$ to remove below-ground data in a similar manner to Boer (1982). Grid points found to be below the ground surface are flagged and their contribution to the integrand in Eqs. (1)-(3) ignored. The term $G_{Z}$ [Eq. (4)] was computed as the residual of the time rate of change of $A_{Z}, C_{Z}$, and $C_{A}$ in order to remove errors associated with computing diabatic heating $\dot{Q}$ at the coarse temporal and spatial resolutions of the reanalysis dataset; we present the equation here to illustrate the contributing terms to $G_{Z}$. Fluxes across the boundaries of the domain $B_{Z}$ (Fig. 1) are not considered, owing to the selection of a domain meant to minimize significant energy transfers across the boundaries (O'Gorman 2010).

Previous studies that have investigated depletions in

\begin{tabular}{|c|c|}
\hline Variable & Description \\
\hline $\begin{array}{l}T, v, \omega, p= \\
\quad \beta(T, v, \omega, p)\end{array}$ & $\beta$ masking for variables \\
\hline$[A]$ & $\begin{array}{l}\text { Zonal average of variable } A \text {, equal to } \\
\qquad(1 / 2 \pi) \int_{0}^{2 \pi} A d \lambda\end{array}$ \\
\hline$\tilde{A}$ & $\begin{array}{l}\text { Meridional average of } A \text {, equal to } \\
\int_{20^{\circ} \mathrm{N}}^{85^{\circ} \mathrm{N}} A \cos \phi d \phi\end{array}$ \\
\hline$A^{\prime \prime}$ & $\begin{array}{l}\text { Perturbation from meridional average of } A \text {, } \\
\quad \text { equal to } A-\tilde{A}\end{array}$ \\
\hline$A^{*}$ & $\begin{array}{l}\text { Perturbation from zonal average of } A \text {, equal } \\
\text { to } A-[A]\end{array}$ \\
\hline$\lambda$ & Longitude $\left({ }^{\circ}\right)$ \\
\hline$\phi$ & Latitude $\left({ }^{\circ}\right)$ \\
\hline$a$ & Average radius of Earth $(\mathrm{m})$ \\
\hline$\gamma$ & $\begin{array}{l}\text { Stability parameter, equal to } \\
\qquad-(\Theta / T)\left[R /\left(c_{p} p\right)\right](\partial \tilde{\Theta} / \partial P)^{-1}\end{array}$ \\
\hline$d m$ & $\begin{array}{l}\text { Mass element corresponding to the bounds } \\
\text { of integration }\left(20^{\circ}-85^{\circ} \mathrm{N}, 180^{\circ} \mathrm{W}-180^{\circ} \mathrm{E} \text {, }\right. \\
1000-100 \mathrm{hPa}) \text {, equal to } a^{2} \cos \phi d \phi d \lambda d p / g\end{array}$ \\
\hline$P$ & Atmospheric pressure $(\mathrm{Pa})$ \\
\hline$\Phi$ & Geopotential height $(\mathrm{m})$ \\
\hline$v$ & Meridional wind component $\left(\mathrm{m} \mathrm{s}^{-1}\right)$ \\
\hline$\omega$ & Vertical velocity $\left(\mathrm{Pa} \mathrm{s}^{-1}\right)$ \\
\hline$T$ & Temperature $(\mathrm{K})$ \\
\hline$\Theta$ & Potential temperature $(\mathrm{K})$ \\
\hline$\dot{Q}$ & Diabatic heating $(\mathrm{K})$ \\
\hline$\kappa$ & $\begin{array}{l}\text { Ratio of gas constant to specific heat, equal } \\
\text { to } R / c_{p}\end{array}$ \\
\hline$c_{p}$ & $\begin{array}{l}\text { Specific heat at constant pressure } \\
\left(1004 \mathrm{~J} \mathrm{~kg}^{-1} \mathrm{~K}^{-1}\right)\end{array}$ \\
\hline$g$ & Gravity $\left(-9.81 \mathrm{~m} \mathrm{~s}^{-2}\right)$ \\
\hline R & Gas constant of dry air $\left(287 \mathrm{~J} \mathrm{~kg}^{-1} \mathrm{~K}^{-1}\right)$ \\
\hline
\end{tabular}
$A_{Z}$ have examined the time rate of change of daily $A_{Z}$ without consideration of the climatology (e.g., Wintels and Gyakum 2000). However, this technique does not
TABLE 1 . Variable definitions for $A_{Z}, G_{Z}, C_{A}$, and $C_{Z}$ calculations.

take into account seasonality in the variance of $A_{Z}$, which is highest (lowest) in winter (summer), thus biasing these results to only identify large changes in $A_{Z}$ in winter months. To address this bias, we compute the standardized anomaly $\sigma$ (Grumm and Hart 2001) of $A_{Z}$, which takes into account both the climatological mean and standard deviation of $A_{Z}$ and therefore is able to capture large changes in $A_{Z}$ relative to a seasonally relevant climatological background state:

$$
A_{Z A}=\frac{A_{Z}-\overline{A_{Z}}}{\overline{\sigma_{A_{Z}}}} .
$$

This value of $A_{Z A}$ is computed using the smoothed daily value of $A_{Z}$, while the daily climatological mean $\overline{A_{Z}}$ and standard deviation $\overline{\sigma_{A_{Z}}}$ are calculated by applying a 90-day low-pass filter to the daily climatology (19792011) of $A_{Z}$. Other filtering techniques were tested for computing the climatological mean and standard deviation, including an 11-, 21-, 31-, and 51-day running 
mean, as well as a 30-day low-pass filter. The 90-day lowpass filter has the lowest standard deviation in all seasons, however, and therefore provides the most accurate estimation of climatological-mean $A_{Z}$ (not shown).

\section{c. Zonal available potential energy buildup event identification scheme}

To diagnose synoptic time scale increases in $A_{Z}$, a seasonally independent framework that captures the short-term variability of the hemispheric energy budget was developed. To identify $A_{Z}$ buildup events, three factors are taken into account: the length and continuity of the event, if the event results in a significant increase in $A_{Z A}$, and whether the ending value of $A_{Z A}$ is anomalous or not. The $A_{Z}$ synoptic-scale buildup event criteria are therefore defined by the following requirements:

1) Events must exceed at least 3 days in length. Events exceeding 10 days must meet criteria 2 and 3 during the final 10 days of the buildup event.

2) The value of $A_{Z A}$ must increase in a near-continuous manner, wherein nonconsecutive daily decreases are permitted. Consecutive decreases in the daily value of $A_{Z A}$ signify the completion of a buildup period, and the buildup period completion day is identified as the final day with increased $A_{Z A}$.

3) The value of $A_{Z A}$ must increase by at least $2 \sigma$ through the duration of the event.

The events identified by these criteria are subdivided based on the value of $A_{Z A}$ at the end of each respective buildup period. Buildup anomalous (BA) events have an ending $A_{Z A}$ exceeding $1.5 \sigma$, while events with an ending $A_{Z A}$ less than $1.5 \sigma$ are termed buildup neutral $(\mathrm{BN})$.

To illustrate this identification technique, a time series of $A_{Z}$ and $A_{Z A}$ for October-December 1999 is shown in Fig. 3. Three buildup events occurred during this period, two of which were 8 days in length (18-26 November and 23-31 December) and classified BN (dashed black). The third event was 11 days in length (30 November11 December), met the criteria for events lasting longer than 10 days, and was classified as BA (solid black).

\section{Results}

\section{a. $A_{Z}$ buildup event climatology}

Applying the $A_{Z}$ buildup event identification scheme, we identify 183 buildup events ( 83 BA and $100 \mathrm{BN}$ ). The occurrence of events is evenly distributed through the different meteorological seasons (46 DJF, 47 MAM, $43 \mathrm{JJA}$, and $47 \mathrm{SON}$ ), with no trend in event occurrence with time (5.5 events per year). BA events more commonly exceed 10 days in duration ( $39 \%$ of events) than
BN events ( $15 \%$ of events), though in both instances, the majority of events are fewer than 10 days in duration. To determine how distinguishable these buildup events ( $n=183$ events) are relative to other $A_{Z}$ increases, we compare identified buildup events to all other $A_{Z A}$ increases $\left(d A_{Z A} / d t>0\right)$ in the 1979-2011 period $(n=930$ events) that do not meet our buildup event criteria. Synoptic buildup events (BA and BN) have an average event duration of 8.6 days, compared to 4.8 days for all other buildup events; an average magnitude of $A_{Z A}$ change of $2.6 \sigma$ versus $0.8 \sigma$; and an average time rate of change of $A_{Z A}$ of $0.30 \sigma$ versus $0.16 \sigma$ day $^{-1}$.

Identified events are decomposed into buildup event type and season, and the event attributes are presented in Table 2. Summer (JJA) events are longest in duration for both BA and BN events, compared to the other seasons. Seasonal differences in the magnitude of increase in $A_{Z A}$ are entirely a function of event duration, with each season and event type exhibiting an average rate of change of $A_{Z A}$ of approximately $0.3 \sigma$ day $^{-1}$. Changes in $A_{Z}$, however, are linked to the seasonal climatology of $A_{Z}$ variability and vary strongly by season (highest in winter, lowest in summer). Differences in the magnitude of buildup of $A_{Z}$ in SON (approximately $9 \times 10^{5} \mathrm{~J} \mathrm{~m}^{-2}$ ) and MAM (approximately $5.7 \times 10^{5} \mathrm{~J} \mathrm{~m}^{-2}$ ) can be explained largely by the background time rate of change of $A_{Z}$ for these transition seasons $\left(-1.94 \times 10^{4} \mathrm{~J} \mathrm{~m}^{-2} \mathrm{day}^{-1}\right.$ for JJA and $2.01 \times 10^{4} \mathrm{~J} \mathrm{~m}^{-2}$ day $^{-1}$ for SON).

The synoptic-time-scale evolution of $A_{Z A}$ for all BA and $\mathrm{BN}$ events is similar (Fig. 4). In both instances, mean $A_{Z A}$ begins to increase 8 days prior to peak $A_{Z}$ day and steadily increases to a peak anomaly on day 0 (peak $A_{Z A}$ day). Following the peak $A_{Z A}$ day, BN events (Fig. 4b) undergo an overall depletion of $A_{Z A}(-0.9 \sigma)$ for the first 5 days after the peak $A_{Z}$ day, at which point $A_{Z A}$ has relaxed to the climatological mean and remains relatively constant through day +10 . BA events (Fig. 4a) undergo a much more rapid decrease in $A_{Z A}$ through day $+5(-1.4 \sigma)$ and continue to decrease through 10 days after the peak $A_{Z}$ day, resulting in a total depletion of $-1.9 \sigma$. When applying a similar identification technique (section 2c) to depletion events, we find that $24 \%$ of BA events are followed by a synoptic-time-scale depletion event, while just $12 \%$ of $\mathrm{BN}$ events are followed by such depletions. This preferred environment for significant depletion events may be of importance for the predictability of significant midlatitude cyclones, which can rapidly deplete $A_{Z}$ (e.g., Bosart et al. 1996).

The buildup of composited $A_{Z}$ is shown in Fig. 5 as a positive time rate of change of $A_{Z}$ (black line) and is time lagged from the end of the composite buildup event (peak $A_{Z}$ day, day 0 ). The time evolution of generation $\left(G_{Z}\right)$ and conversion $\left(C_{A}, C_{Z}\right)$ terms are composited by 

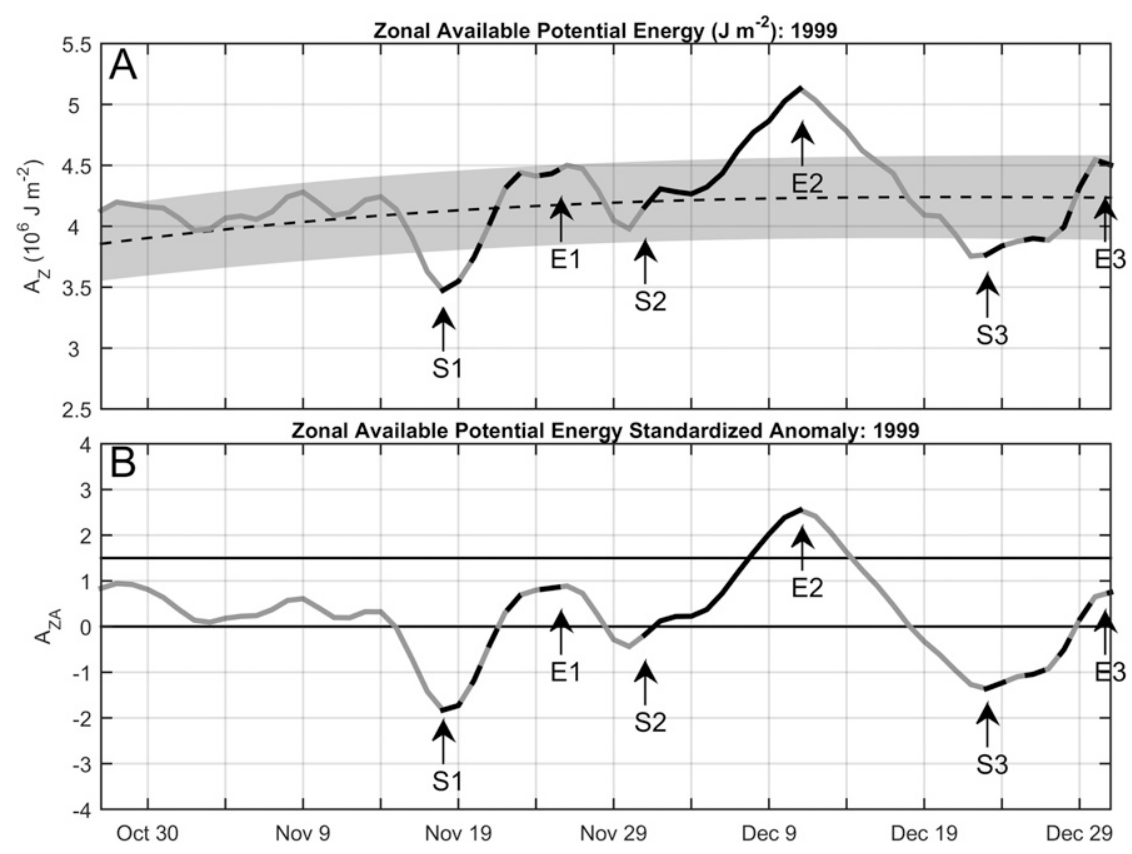

FIG. 3. The 28 Oct-31 Dec 1999 time series of identified $A_{Z A}$ buildup events. (a) Daily $A_{Z}$ (thin gray), 90-day low-pass-filtered running-mean $A_{Z}$ climatological mean (thin black dashed), 90-day low-pass-filtered running-mean climatological standard deviation of $A_{Z}$ ( $\pm 1 \sigma$ envelope, gray shading), and identified BA $(\mathrm{BN})$ buildup events [thick black solid (thick black dashed)]. (b) Daily, 3-day running-mean $A_{Z A}$ and identified BA (BN) buildup events [thick black solid (thick black dashed)], with the $0 \sigma$ and $1.5 \sigma$ thresholds highlighted (medium black). Three events are identified by starting dates [S1 (18 Nov), S2 (30 Nov), and S3 (23 Dec)] and ending dates [E1 (26 Nov), E2 (11 Dec), and E3 (31 Dec)] and have corresponding changes in $A_{Z A}$ of $2.54 \sigma, 2.71 \sigma$, and $2.06 \sigma$, respectively.

season and buildup type, providing insight into the processes contributing to synoptic-scale increases in $A_{Z}$. Seasonal-mean values of $G_{Z}$ (blue) and $C_{A}$ (red) are closely tied to the annual cycle of $A_{Z}$, with highest values in the winter $\left(4-6 \mathrm{~W} \mathrm{~m}^{-2}\right)$ and lowest in the summer (0-2 $\mathrm{W} \mathrm{m}^{-2}$; Figs. 5e,f; note the change in axis limits), while the total term of $C_{Z}$ (turquoise) exhibits little seasonal variability and contributes minimally to the budget of $A_{Z}$ (Figs. 5a-h). Consequently, synoptic buildup events are dominated by $G_{Z}$ and $C_{A}$, consistent with previous studies (e.g., Oort 1964; Oort and Peixóto 1976; Veiga et al. 2008; Pezza et al. 2010).

The buildup of $A_{Z}$ is modulated by an increase in $G_{Z}$ and a decrease in $C_{A}$, both of which would act to increase $A_{Z}$. DJF BA, SON BA, and SON BN events have larger increases in $G_{Z}$ than decreases in $C_{A}$, indicating that diabatic heating and cooling processes acting to enhance the hemispheric meridional temperature gradient

TABLE 2. NH $A_{\mathrm{ZA}}$ buildup event climatology: 1979-2011. In cells with two numbers, the format is mean/std dev.

\begin{tabular}{|c|c|c|c|c|}
\hline & DJF & MAM & JJA & SON \\
\hline Event count: BA & 18 & 25 & 17 & 23 \\
\hline Event count: BN & 28 & 22 & 26 & 24 \\
\hline Event length: BA (days) & $8.9 / 1.5$ & $8.8 / 1.2$ & $9.2 / 1.3$ & $8.7 / 1.7$ \\
\hline Event length: BN (days) & $8.3 / 1.4$ & $8.4 / 1.7$ & $8.5 / 1.6$ & $8.3 / 1.8$ \\
\hline$\Delta A_{Z}: \mathrm{BA}\left(10^{5} \mathrm{~J} \mathrm{~m}^{-2}\right)$ & $9.0 / 1.4$ & $5.8 / 2.5$ & $3.3 / 2.1$ & $9.8 / 1.5$ \\
\hline$\Delta A_{Z}: \mathrm{BN}\left(10^{5} \mathrm{~J} \mathrm{~m}^{-2}\right)$ & $8.8 / 1.2$ & $5.7 / 2.0$ & 2.3/1.6 & $8.1 / 1.0$ \\
\hline$\Delta A_{Z}:$ Climatology $\left(10^{3} \mathrm{~J} \mathrm{~m}^{-2}\right.$ day $^{-1}$; mean $)$ & 0.60 & -19.4 & -0.12 & 20.1 \\
\hline$\Delta A_{\mathrm{ZA}}: \mathrm{BA}(\sigma)$ & $2.6 / 0.40$ & $2.7 / 0.5$ & $3.0 / 0.7$ & $2.8 / 0.5$ \\
\hline$\Delta A_{\mathrm{ZA}}: \mathrm{BN}(\sigma)$ & $2.4 / 0.3$ & $2.5 / 0.5$ & $2.5 / 0.4$ & $2.3 / 0.3$ \\
\hline End $A_{Z A}: \mathrm{BA}(\sigma)$ & $2.2 / 0.8$ & $2.2 / 0.5$ & $2.2 / 0.7$ & $2.2 / 0.5$ \\
\hline End $A_{Z A}: \mathrm{BN}(\sigma)$ & $0.8 / 0.5$ & $0.9 / 0.6$ & $0.9 / 0.5$ & $0.9 / 0.4$ \\
\hline
\end{tabular}



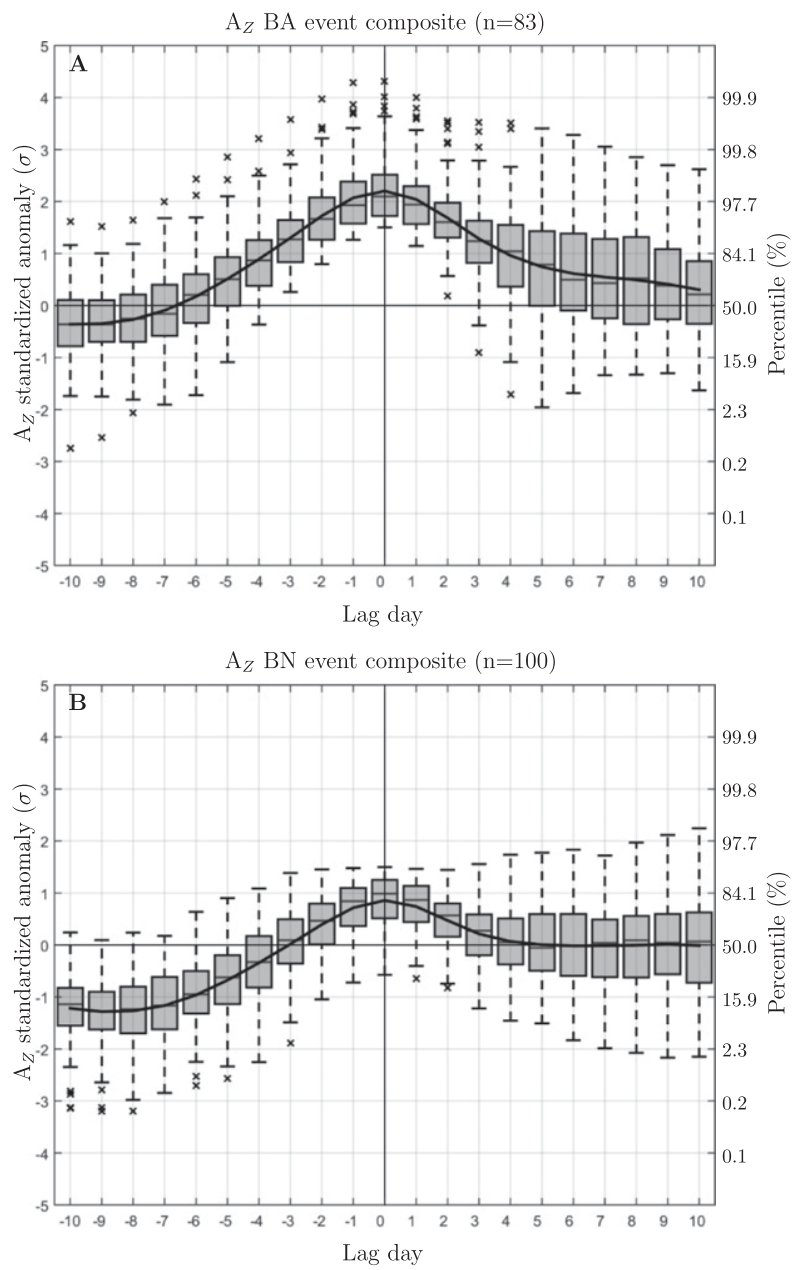

FIG. 4. Statistical distribution of (a) $83 A_{Z}$ BA events and (b) 100 $A_{Z}$ BN events from 1979 to 2011 for days -10 to +10 , centered on day 0 (end of $A_{Z}$ buildup event). Upper and lower edges of each box represent the 25 th and 75 th percentiles, whisker edges dictate the 1st and 99th percentiles, and black $\times$ marks denote outliers. The thick black line denotes the event climatology mean value of $A_{Z}$ for BA and BN events.

may be the dominant processes during such $A_{Z}$ buildup events (Figs. 5a,g,h). The baroclinic conversion signature (rapid increase in $C_{A}$ ) noted from days 0 to +4 for each buildup event is similar to those noted for cyclogenesis events in Pezza et al. (2010). This indicates that robust midlatitude cyclone activity, which could capitalize on the enhanced regional or hemispheric baroclinic instability associated with an $A_{Z}$ buildup, likely has an important role in concluding buildup events.

\section{b. Synoptic evolution: DJF buildup events}

To examine some of the extratropical synoptic features associated with winter buildups in $A_{Z}$, a brief diagnosis of changes to daily composite-mean tropospheric mass, temperature, and moisture fields is performed for DJF
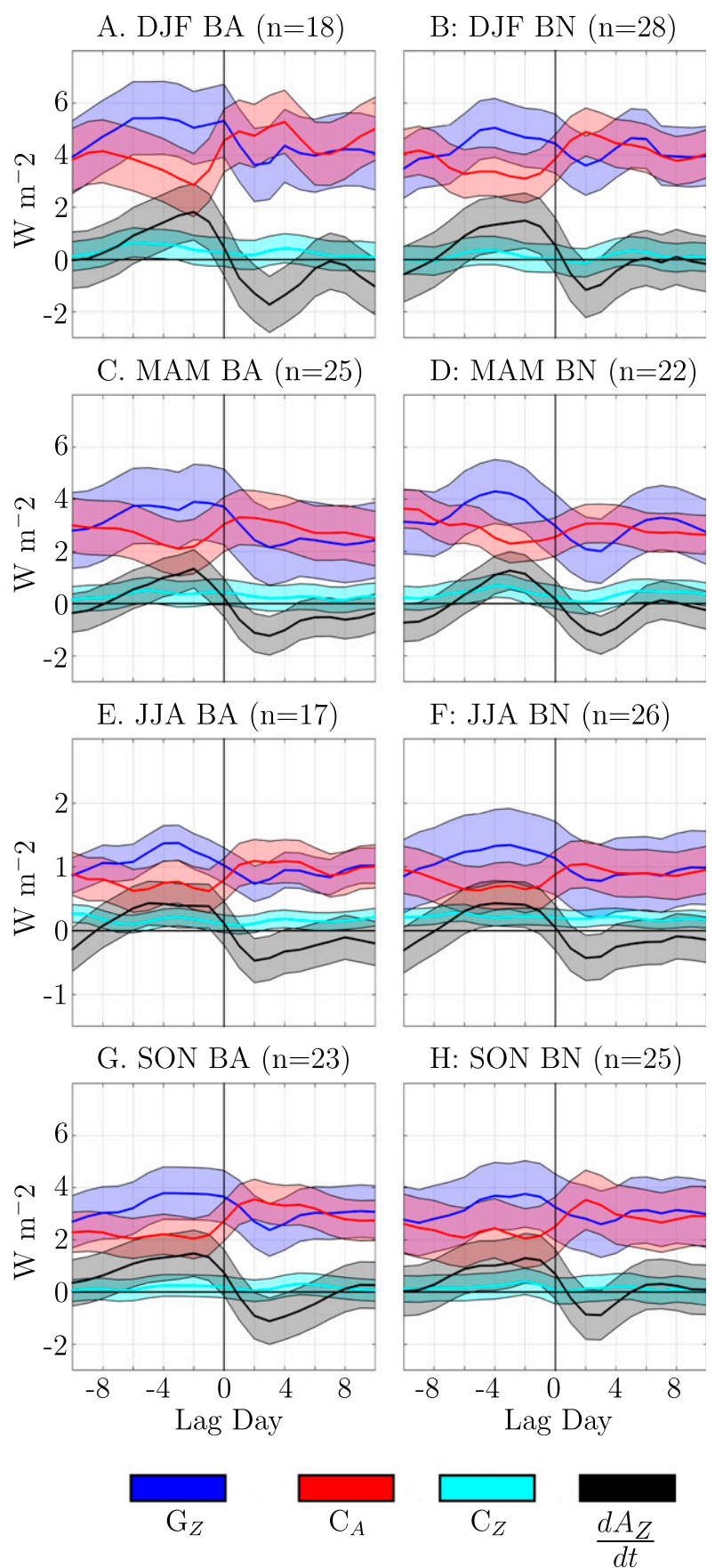

FIG. 5. Seasonal (a),(c),(e),(g) BA and (b),(d),(f),(h) BN event daily composite-mean $\left(\mathrm{W} \mathrm{m}^{-2}\right) G_{Z}$ (blue line), $C_{A}$ (red line), $C_{Z}$ (turquoise line), and time rate of change of $A_{Z}$ (black line) and standard deviation ( $\pm 1 \sigma$ envelope, corresponding color shading) for days -10 to +10 . Ranges of values for (a) $-(d),(g)$, and (h) are -3 to $8 \mathrm{~W} \mathrm{~m}^{-2}$ and for (e) and (f) are -1.5 to $3 \mathrm{~W} \mathrm{~m}^{-2}$.

BA and BN events. A qualitative assessment of processes acting to increase $G_{Z}$ (differential diabatic heating or cooling acting to increase the hemispheric baroclinicity) and to reduce $C_{A}$ (reductions in thermally direct eddy 
circulations that act to release baroclinic instability) will be performed. Such processes include large-scale deformation, temperature advection, and diabatic sources of heating or cooling. The analysis is presented as days prior to the final day of an $A_{Z}$ buildup event when the peak $A_{Z}$ occurs, and the DJF BA and BN event composites will be compared and contrasted.

Changes to the mean lower-tropospheric temperature can be assessed for the midlatitudes $\left(20^{\circ}-50^{\circ} \mathrm{N}\right)$ and high latitudes $\left(50^{\circ}-85^{\circ} \mathrm{N}\right)$ by analyzing changes to the 1000 500-hPa event composite thickness field (Fig. 6). Despite notable differences in the high-latitude $\left(50^{\circ}-80^{\circ} \mathrm{N}\right)$ 1000-500-hPa-thickness anomaly values, both BA and $\mathrm{BN}$ events have thickness reductions that occur predominantly in the North Pacific $\left(180^{\circ}-140^{\circ} \mathrm{W}\right)$ and are on the order of $120 \mathrm{~m}$ (approximately $6^{\circ} \mathrm{C}$ of cooling; Figs. 6a,c). In the midlatitudes, 1000-500-hPa compositemean thickness increases of $30 \mathrm{~m}$ are noted for both BA and BN events (Figs. 6b,d). This regional enhancement of the meridional temperature gradient emerges as the dominant coherent feature in the hemisphere and is therefore most likely attributable to the increase in $A_{Z}$. Consequently, the majority of our analysis will focus on this region.

This regional focus is further emphasized by changes to the dynamic tropopause and lower-tropospheric mean temperature fields (Fig. 7). In both DJF BA and BN event composites, regions near Alaska undergo a transition from a thermal ridge at the dynamic tropopause level to a thermal trough through the duration of the buildup period (Fig. 7, black line). A thermal trough on the dynamic tropopause is indicative of a lower tropopause height and is often associated with a colder mean troposphere, as denoted by the 1000-500-hPathickness anomalies (Fig. 7), while the opposite is true for a thermal ridge. These patterns also reflect the transition in the mass fields from a ridge to a trough due to the equivalent barotropic orientation of mass and temperature fields in the free atmosphere. Significant differences remain between the two composite events, however. Nine days prior to the end of the composite BA buildup event (day -9), the Northern Hemisphere is generally lacking in coherent composite anomalies in the midlatitude flow, as indicated by a lack of 1000-500-hPa-thickness anomalies or dynamic tropopause wind anomalies (Fig. 7a). This period also corresponds to unremarkable $A_{Z}$ anomalies near $0 \sigma$ (Fig. 4a). A robust couplet of positive (60 to $90 \mathrm{~m}$ ) and negative $(-150$ to $-120 \mathrm{~m})$ thickness anomalies develops by the end of the composite BA event near $180^{\circ}-110^{\circ} \mathrm{W}$ (Fig. 7b). This regional enhancement in lower-tropospheric temperature gradient is associated with a corresponding elongation of the North Pacific jet into western North
America with dynamic tropopause westerly anomalies of $35 \mathrm{kt}\left(1 \mathrm{kt}=0.51 \mathrm{~m} \mathrm{~s}^{-1}\right)$, consistent with the regional enhancement in thermal wind (Fig. 7b).

In contrast to the onset of the composite BA event, a robust ridge-trough pattern is noted over North America for the onset of the composite BN event (Fig. 7c). Thickness anomalies of 90-120 $\mathrm{m}$ are noted near the Bering and Chukchi Seas region in association with this pattern, while thickness anomalies associated with the trough over eastern North America exceed $-120 \mathrm{~m}$. Dynamic tropopause wind anomalies in association with this trough indicate anomalous northerlies (southerlies) to the west (east) of the trough of $20 \mathrm{kt}$ (Fig. 7c). Furthermore, a -30 - to $-60-\mathrm{m}$ negative thickness anomaly is noted over East Asia during this period. These patterns are both associated with cold-air outbreak events, which are known patterns associated with $A_{Z}$ depletion events (e.g., Lau and Lau 1984; Wintels and Gyakum 2000; Garreaud 2001). When applying a similar identification technique (section 2c) to depletion events, we find that $16 \%$ of BN events are preceded by a synoptic-time-scale depletion event, compared to just $8 \%$ for BA events. By the end of the BN composite period, areas near the Bering and Chukchi Seas have undergone a robust cooling (-60- to $-90-\mathrm{m}$ thickness anomalies) in association with the development of a thermal trough on the dynamic tropopause (Fig. 7d). Other regions in the Northern Hemisphere, however, are generally lacking in coherent composite mass field anomalies as $A_{Z}$ anomalies approach $0 \sigma$ (Fig. 4b).

Further diagnosis of the thermodynamic changes to the troposphere associated with these composite buildup events will now be discussed in the context of the thermodynamic equation

$$
\frac{\partial T}{\partial t}=-\mathbf{v} \cdot \nabla_{P} T-\omega\left(\frac{\alpha}{c_{p}}-\frac{\partial T}{\partial P}\right)+\frac{1}{c_{p}} \frac{d Q}{d t},
$$

where $\partial T / \partial t$ refers to the local rate of change of temperature, $\mathbf{v} \cdot \nabla_{p} T$ diagnoses the contribution from horizontal temperature advection, $\omega\left(\alpha / c_{p}-\partial T / \partial P\right)$ diagnoses the contribution from adiabatic heating or cooling and vertical advection, and $\left(1 / c_{p}\right)(d Q / d t)$ represents diabatic contributions to heating or cooling.

Significant changes to the BA event composite-mean airmass properties of the eastern Pacific basin begin around day -6 , as an extensive region of anomalously high thickness develops in the equatorward exit region of the North Pacific jet $\left(40^{\circ} \mathrm{N}, 180^{\circ}-150^{\circ} \mathrm{W}\right.$; Fig. 8 a). This positive thickness anomaly propagates eastward and remains confined to the $40^{\circ} \mathrm{N}, 180^{\circ}-120^{\circ} \mathrm{W}$, region for day -6 through the peak $A_{Z}$ day, anchoring an area of anomalous warmth on the equatorward side of the North 
A. DJF BA, $50^{\circ}-80^{\circ} \mathrm{N}$

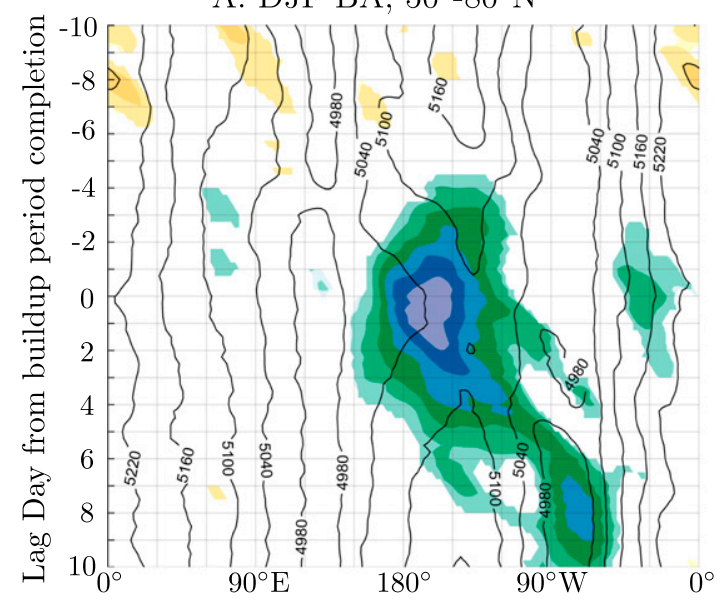

B. DJF BA, $20^{\circ}-50^{\circ} \mathrm{N}$
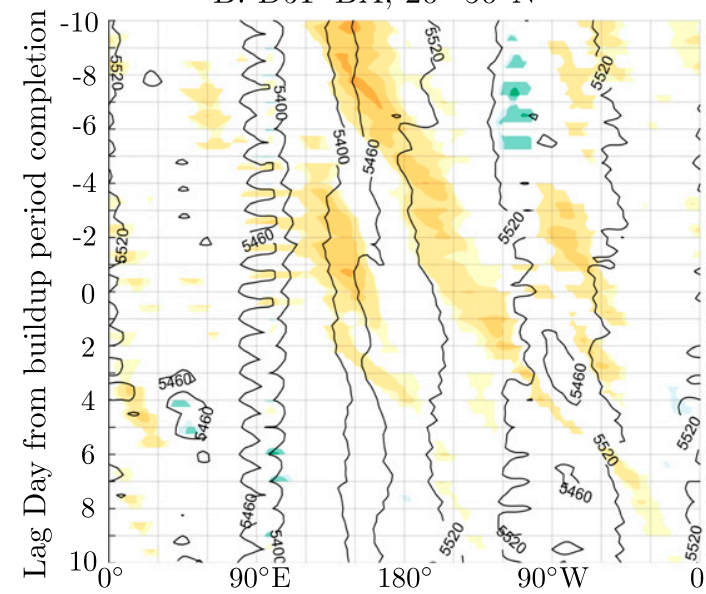

C. DJF BN, $50^{\circ}-80^{\circ} \mathrm{N}$
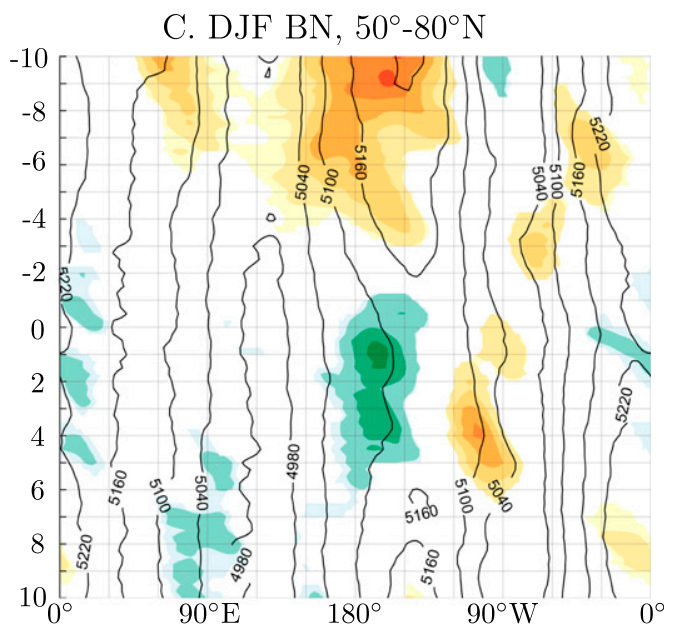

D. DJF BN, $20^{\circ}-50^{\circ} \mathrm{N}$

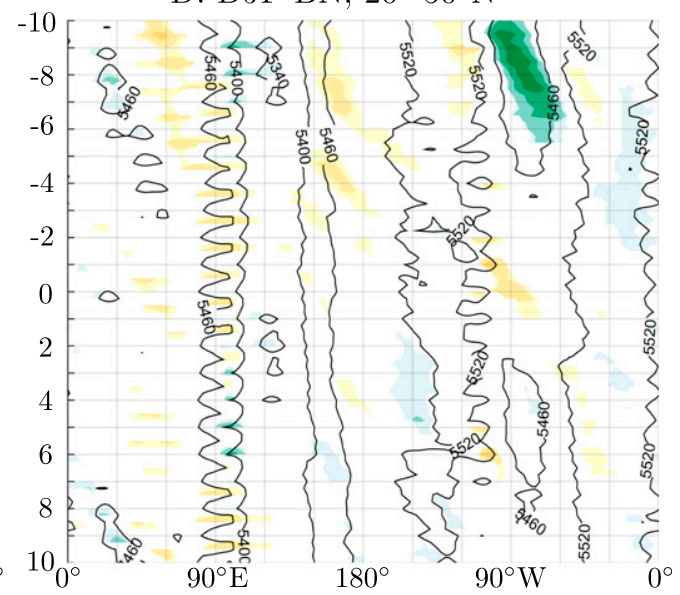

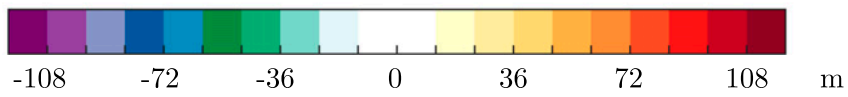

FIG. 6. DJF (a),(b) BA ( $n=18$ events) and (c),(d) BN ( $n=28$ events) event composite-mean Hovmöller diagrams of $1000-500-\mathrm{hPa}$ thickness (60-m contour interval; solid black) and anomaly from DJF climatology (colored; $12-\mathrm{m}$ contour interval) computed for the (a),(c) $50^{\circ}-80^{\circ}$ and (b),(d) $20^{\circ}-50^{\circ} \mathrm{N}$ bands. Shaded anomalies are shown only when significant at the $90 \%$ level, computed using a two-sided Student's $t$ test.

Pacific jet exit region (Figs. 8a-c). The anomalous anticyclonic dynamic tropopause wind circulation that develops near $150^{\circ} \mathrm{W}$ in association with this warm anomaly is preferentially characterized by easterly (northerly) anomalies in the dynamic tropopause wind on the southern (eastern) flank of the thickness anomaly (Figs. 8a-c). The orientation of this pattern of wind and thickness anomalies is synonymous with that of anticyclonic wave breaking, which will be elaborated upon further in the discussion.

Regions of warm-air advection are noted in the region equatorward of the North Pacific jet for the composite BA event, as denoted by surface geostrophic southwesterly flow advecting higher thickness values northward along the western flank of the subtropical high (Figs. 8a-c). Further analysis of this warming is assessed through analysis of vertical velocity $\omega$, relative humidity, and condensational heating rates (CNHRs) for the $150^{\circ} \mathrm{W}$ cross section (Figs. 9a,b). The CNHR is calculated as

$$
\mathrm{CNHR}=-\left(\frac{1}{g}\right) \int_{1000 \mathrm{hPa}}^{200 \mathrm{hPa}} \omega\left(\frac{\partial r_{s}}{\partial P}\right)_{\mathrm{ma}} d P
$$

where the CNHR is taken to be the same as the precipitation rate, $r_{s}$ is the saturation mixing ratio, and the subscript "ma" represents the moist adiabat most appropriate for the calculation (Gyakum 2008). 

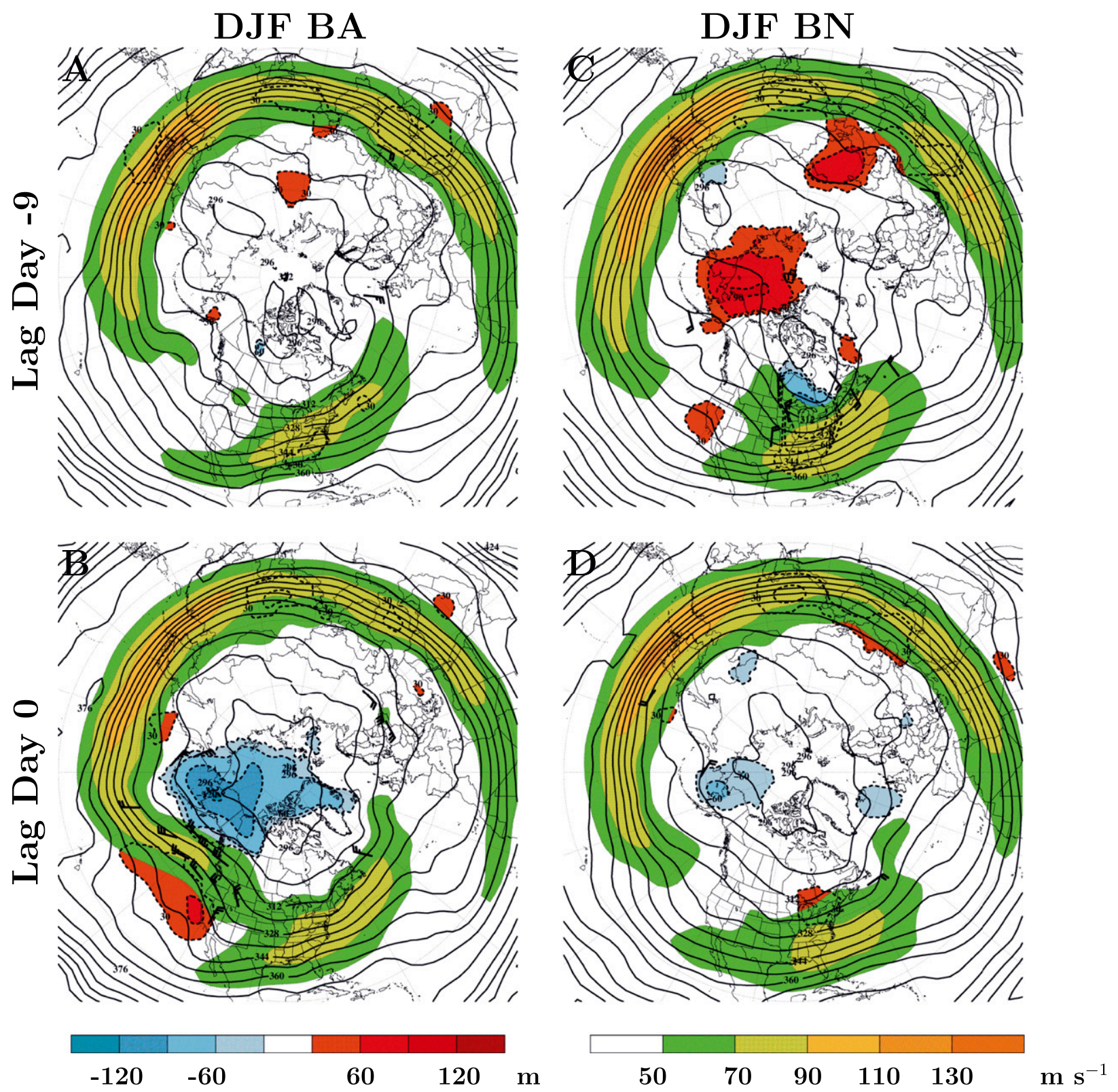

FIG. 7. DJF (a),(b) BA and (c),(d) BN event composite-mean dynamic tropopause wind exceeding $50 \mathrm{kt}$ (shaded; 20-kt contour interval from $50 \mathrm{kt}$ ), wind anomaly from weighted DJF climatology (flags; beginning at $20 \mathrm{kt}$, with typical meteorological convention), dynamic tropopause potential temperature (thick black contour; 8-K interval), and 1000-500-hPa thickness anomaly from weighted DJF climatology (dashed black contour and colored; 30-m interval) for days (a),(c) -9 and (b),(d) 0 (peak $A_{Z}$ day). Dynamic tropopause wind and potential temperature fields are smoothed using a five-point smoother, and thickness anomalies are only shown when significant at the $95 \%$ level, computed using a two-sided Student's $t$ test.

Condensational heating at $150^{\circ} \mathrm{W}$ on day -7 is noted near $45^{\circ} \mathrm{N}$ (Fig. 9a) in the eastward-propagating positive thickness anomaly in the North Pacific (Fig. 8b). Adiabatic warming associated with descent in response to the tropospheric-deep anticyclonic anomaly also likely contributes to warming in this region, though regions of robust subsidence were not extensive (not shown). It is therefore indicative that warm-air advection and diabatic heating have an important role in heating the equatorward flank of the jet during this time.

The robust cooling of the high latitudes from $160^{\circ} \mathrm{E}$ to $120^{\circ} \mathrm{W}$ occurs primarily from day -6 to day 0 for both the BA and BN event composites (Figs. 6, 8). In both instances, areas of eastern Alaska and the Northwest Territories of Canada are subject to warm-air advection, 
DJF BA

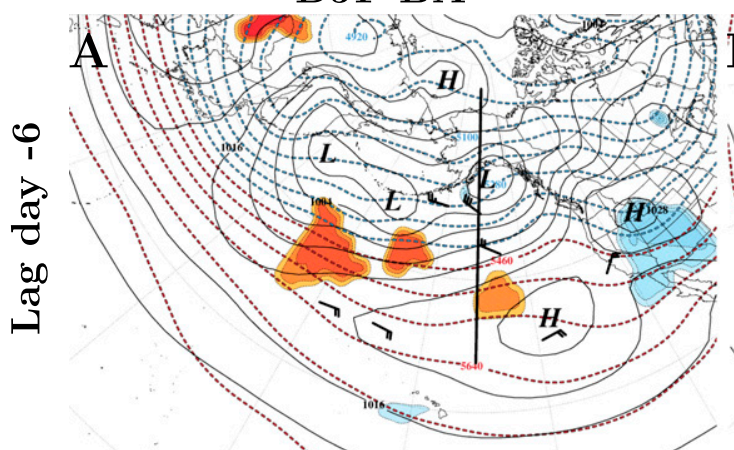

\section{DJF BN}
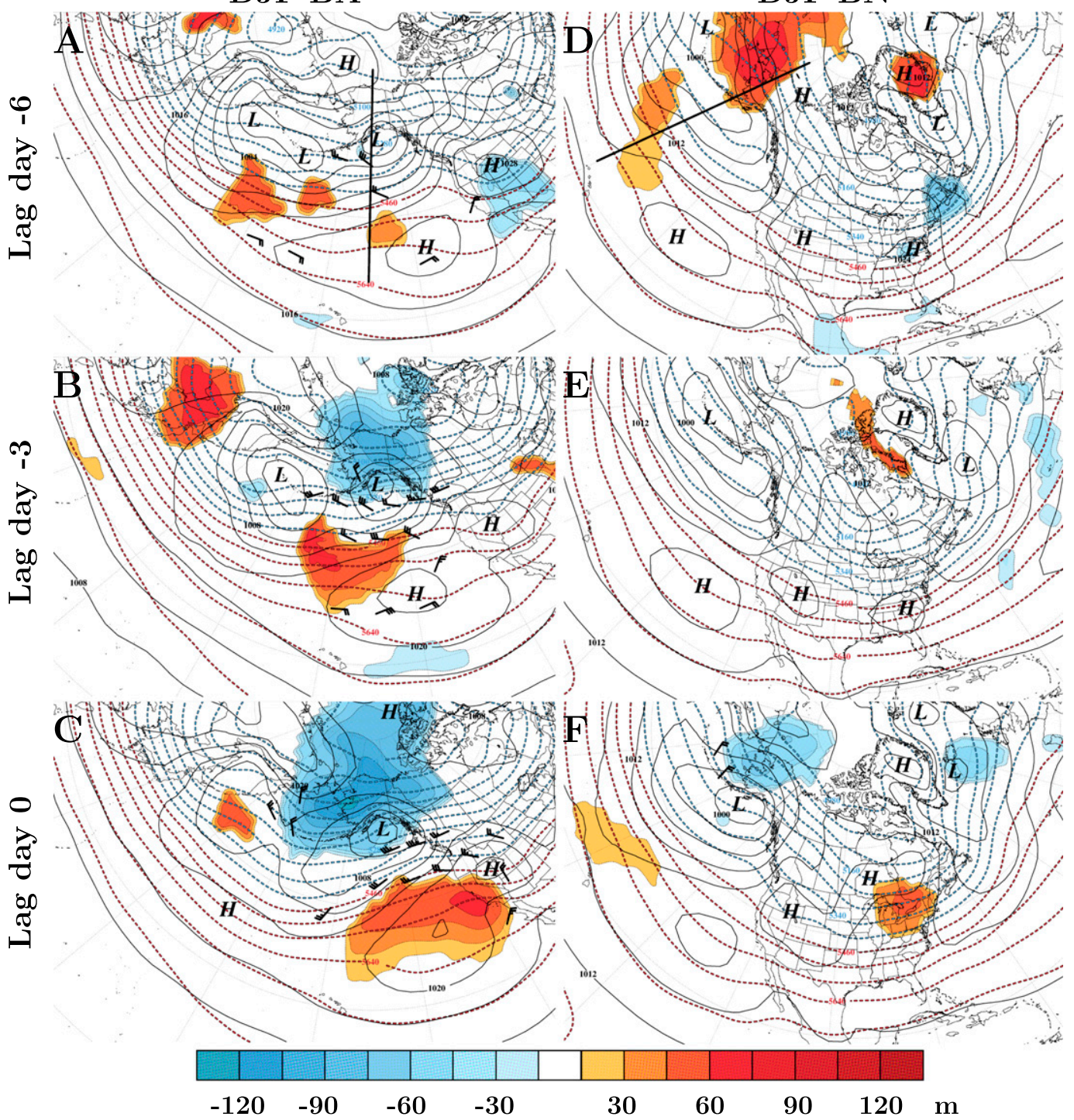

FIG. 8. DJF (a)-(c) BA and (d)-(f) BN event composite-mean 1000-500-hPa thickness [dashed blue ( $\leq 5400 \mathrm{~m})$ and red $(>5400 \mathrm{~m}) ; 60-\mathrm{m}$ contour intervals], 1000-500-hPa thickness anomaly from weighted DJF climatology (colored; $\mathrm{m}$ ), and sea level pressure (thin black contour; 4-hPa contour interval) for days (a),(d) -6, (b), (e) -3, and (c),(f) 0 (end of composite buildup event). The 1000-500-hPa thickness and sea level pressure fields are smoothed using a five-point smoother, and thickness anomalies are only shown when significant at the $95 \%$ level, computed using a two-sided Student's $t$ test. Thick black line at (a) $25^{\circ}-75^{\circ} \mathrm{N}, 150^{\circ} \mathrm{W}$ and (d) $25^{\circ}-75^{\circ} \mathrm{N}, 160^{\circ} \mathrm{W}$ corresponds to the cross section for Fig. 9.

as denoted by surface geostrophic southeasterly flow advecting higher thickness values northward along the eastern flank of the composite low-pressure system in the Gulf of Alaska (Figs. 8a-c). Interestingly, reductions in 1000-500-hPa thickness in this region are observed for the BA event composite but not for the BN event composite (Figs. 8c,f). This apparent discrepancy will be elaborated upon in the discussion. Regions over central and western Alaska are generally subject to neutral to weak cold (warm)-air advection for the BA (BN) event composite (Figs. 8c,f). Cold-air advection over the Bering and Chukchi Seas region is associated with the consolidation of the surface composite low in the Gulf of Alaska by day 0 for both BA and BN event composites (Figs. 8c,f).

To further diagnose the cooling mechanisms in this region, cross sections are presented near the center of maximum cooling for the BA $\left(150^{\circ} \mathrm{W}\right.$; Figs. 9a,b) and BN event composites $\left(160^{\circ} \mathrm{W}\right.$; Figs. $\left.9 \mathrm{c}, \mathrm{d}\right)$. The results are presented to represent two distinct periods for both BA 


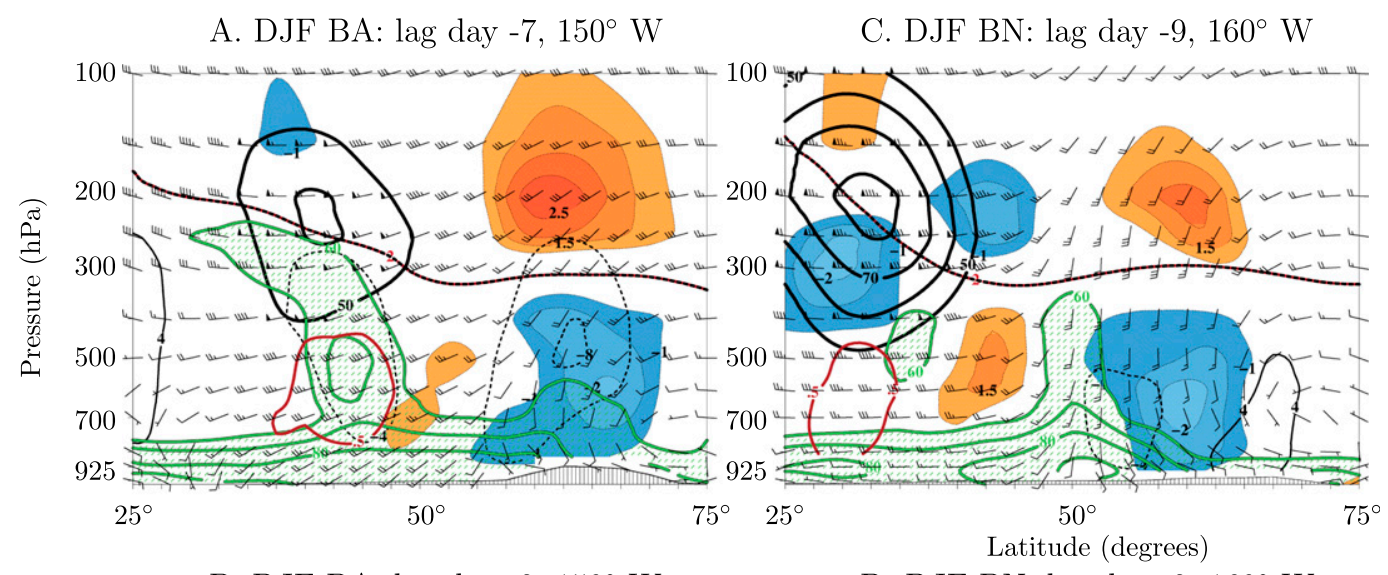

B. DJF BA: lag day $-2,150^{\circ} \mathrm{W}$

D. DJF BN: lag day $-2,160^{\circ} \mathrm{W}$

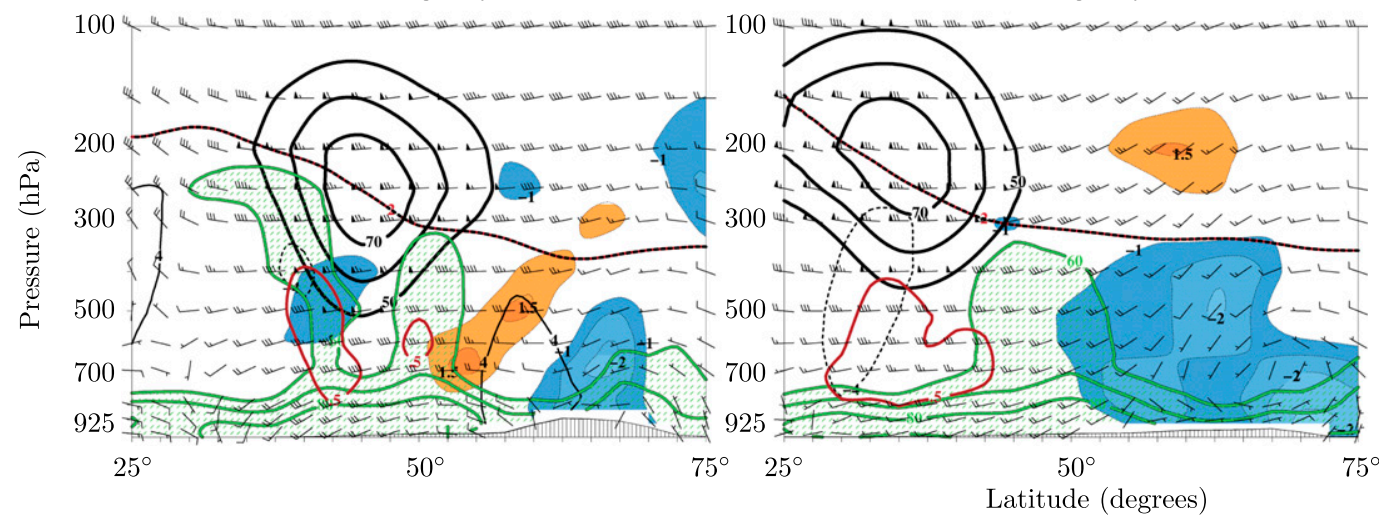

FIG. 9. (a) Day -7 and (b) day -2 DJF BA event composite cross sections for the 1000-100-hPa layer for $25^{\circ}-$ $75^{\circ} \mathrm{N}, 150^{\circ} \mathrm{W}$. (c) Day -9 and (d) day $-2 \mathrm{DJF}$ BN event composite cross sections for $25^{\circ}-75^{\circ} \mathrm{N}, 160^{\circ} \mathrm{W}$. Plotted is daily mean wind magnitude (thick black; 10 -kt interval from $50 \mathrm{kt}$ ), daily mean Cartesian wind direction and speed (flags; typical meteorological convention), daily mean vertical velocity $\omega$ (thin black; $4 \times 10^{-4} \mathrm{~Pa} \mathrm{~s}^{-1}$ interval; dashed negative), daily mean relative humidity (green hatched; $10 \%$ interval from $60 \%$ ), daily mean dynamic tropopause [2 potential vorticity unit (PVU; $1 \mathrm{PVU}=10^{-6} \mathrm{~K} \mathrm{~kg}^{-1} \mathrm{~m}^{2} \mathrm{~s}^{-1}$ ) surface; red-black dashed thick], daily mean condensational heating rate (red thick; $0.5 \times 10^{-1} \mathrm{~K}^{-1 a y}{ }^{-1}$ interval), and 24 -h time rate of change of temperature centered on map analysis period [shaded red (positive) and blue (negative); $0.5 \mathrm{~K} \mathrm{day}^{-1}$ interval].

and $\mathrm{BN} A_{Z}$ buildup periods, which occur at different points in the respective composite events: 1) a period of poleward moisture flux and ascent into the high latitudes (Figs. 9a,c) and 2) a period of high-latitude isolation and cooling (Figs. 9b,d). Warm-air advection, as indicated by veering winds with height, is noted from $50^{\circ}$ to $70^{\circ} \mathrm{N}$ for BA event composite day -7 and BN event composite day -9 (Figs. 9a,c). These regions are also subject to cloud layers (ascertained from event composite-mean relative humidity exceeding $60 \%$ ) up to $700 \mathrm{hPa}$ and diagnosed ascent (Figs. 9a,c). Furthermore, moisture flux convergence (negative divergence) of up to $-6 \times 10^{-8} \mathrm{~g} \mathrm{~kg}^{-1} \mathrm{~s}^{-1}$ is noted in both event composites (Figs. 10a,c).

In the second period, regions from $60^{\circ}$ to $70^{\circ} \mathrm{N}$ are broadly subject to surface easterly flow, neutral temperature advection, and a thinning of the layer of lower-tropospheric clouds to cloud heights of approximately $900 \mathrm{hPa}$ (Figs. 9b,d). During this period, moisture flux convergence into this region reduces to negligible values, and a net drying of the column precipitable water occurs, with reductions of $2-3 \mathrm{~mm}$ for the BA event composite and $1-2 \mathrm{~mm}$ for the $\mathrm{BN}$ event composite (Figs. 10b,d). This process of moist ascent in a cold atmosphere, followed by an isolation of the region from any vertical motion or temperature advections, indicates that diabatic processes likely play an important role in cooling the high latitudes for both event composites. Such diabatic processes could contribute to cooling through evaporation or sublimation, as well as radiative cooling from the surface and cloud tops. These processes have further been shown to be an important contribution to both cold-airmass generation (Turner et al. 2013) and $A_{Z}$ generation (Romanski and Rossow 2013). As such, we 
A. DJF BA: lag day -7

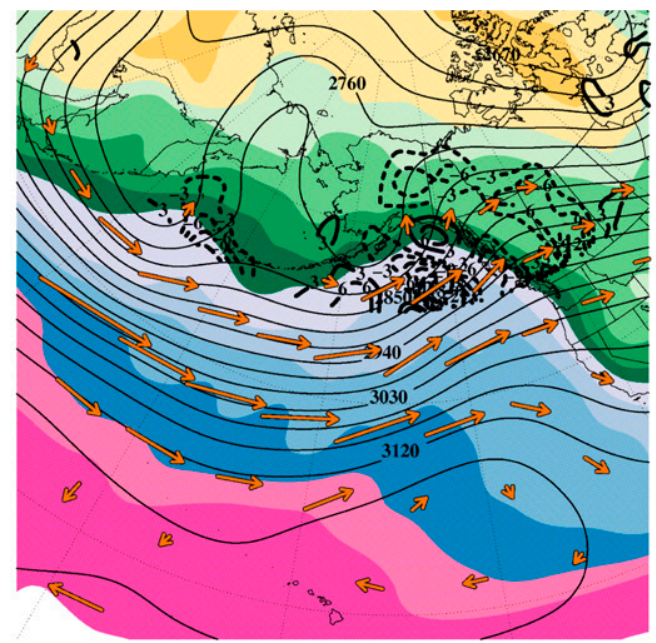

B. DJF BA: lag day -2

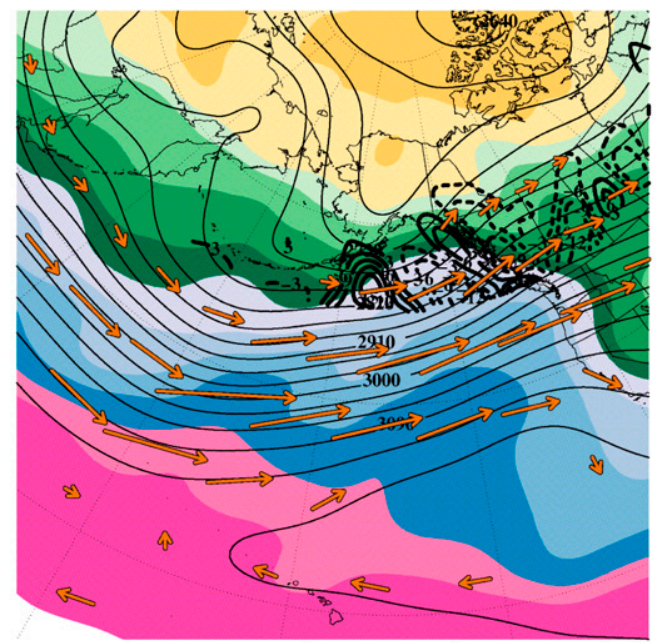

C. DJF BN: lag day -9

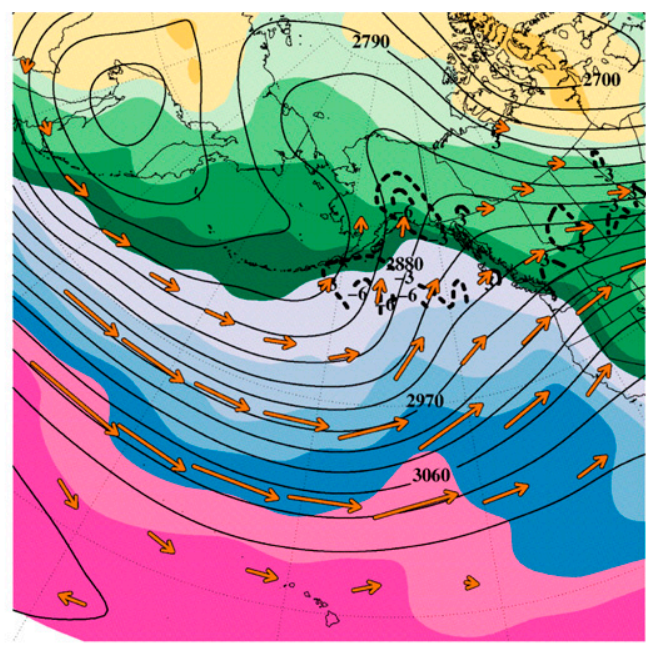

D. DJF BN: lag day -2

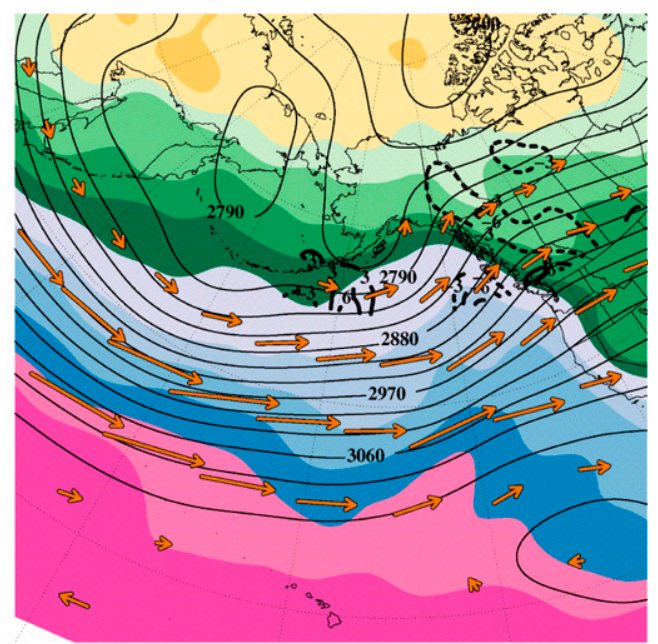

$\Longrightarrow 20 \mathrm{~m} \mathrm{~s}^{-1}$ reference vector

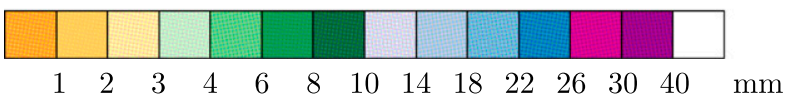

FIG. 10. 700-hPa heights (thin black; 30-m contour), precipitable water (mm; colored), moisture flux (orange arrows; $10^{-2} \mathrm{~m} \mathrm{~s}^{-1}$ ), and moisture flux convergence (dashed black: convergence; solid black: divergence; masked south of $50^{\circ} \mathrm{N} ; 3 \times 10^{-8} \mathrm{~g} \mathrm{~kg}^{-1} \mathrm{~s}^{-1}$ contour) for DJF BA event composite (a) day -7 and (b) day -2 and DJF BN event composite (c) day -9 and (d) day -2 .

introduce a results-based framework for $A_{Z}$ generation on synoptic scales in the discussion section.

The role of mid- and high-latitude Rossby waves in perturbations to $C_{A}$ are next diagnosed through Hovmöller diagrams of latitudinal-mean $20^{\circ}-50^{\circ} \mathrm{N}$ and $50^{\circ}-80^{\circ} \mathrm{N}$ dynamic tropopause meridional winds and $C_{A}$ (Figs. 11, 12). A coherent composite-mean northerly anomaly is noted in the high latitudes for the BA event composite near $180^{\circ}$ for days -7 to 0 , which is collocated with a negative $C_{A}$ anomaly (Figs. 11a,b). This region of anomalous northerly flow is generally on the eastern flank of the dynamic tropopause ridge in this region, also resulting in implied anticyclonic vorticity advection and descent. The role of this anomalous flow, therefore, could result in negative contributions to both terms in Eq. (2) and will be further speculated on in the discussion. No other coherent anomalous high-latitude meridional flow is noted during the BA composite period, which, when considered with the widespread low $C_{A}$ anomalies (Fig. 11b), implies anomalously low occurrences of Rossby waves for this period. 

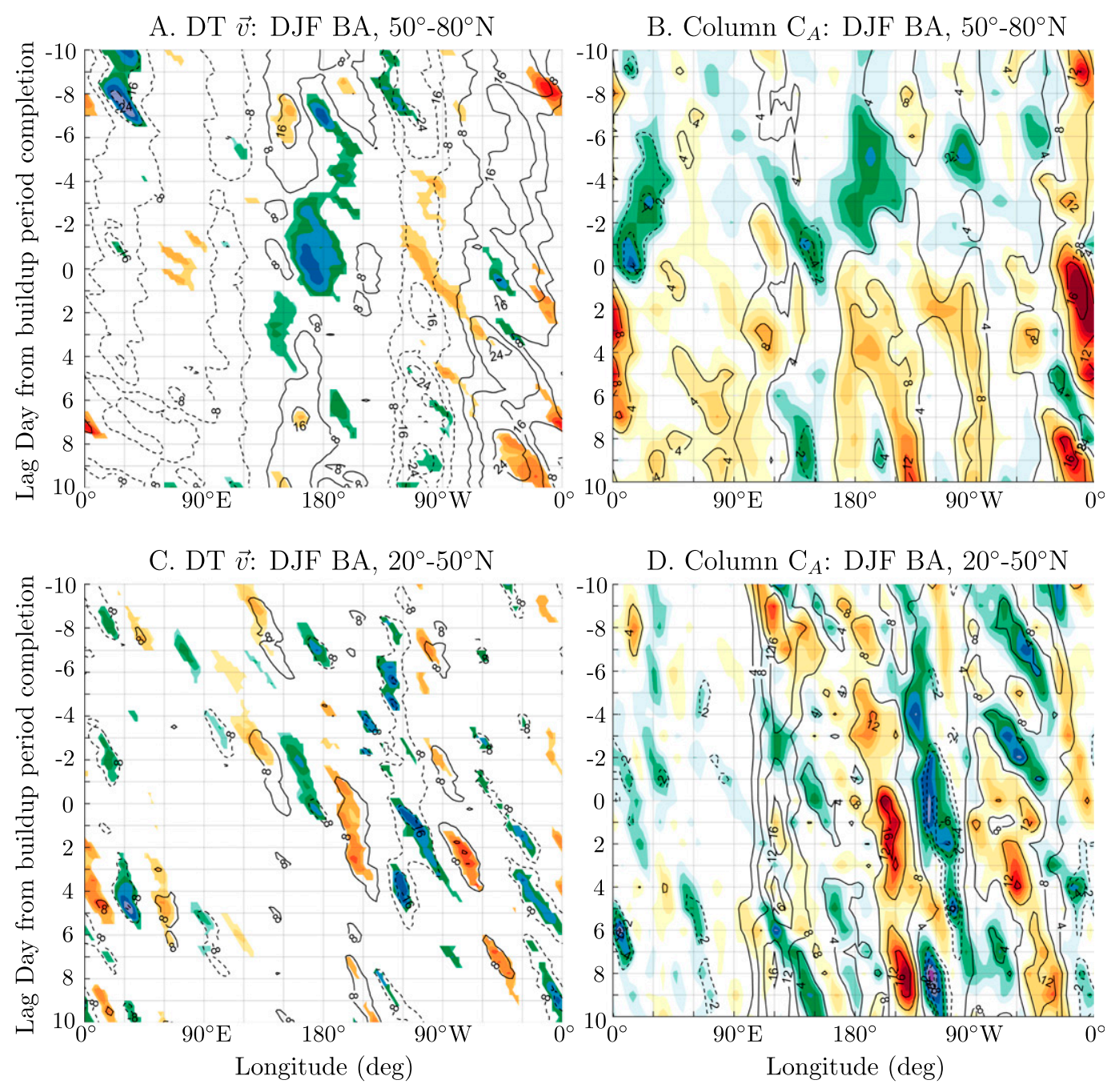

\begin{tabular}{|c|c|c|c|c|c|c|c|}
\hline-18 & -12 & -6 & 0 & 6 & 12 & 18 & $\mathrm{~m} \mathrm{~s}^{-1}$ \\
\hline-9 & -6 & -3 & 0 & 3 & 6 & 9 & $\mathrm{~W} \mathrm{~m}^{-2}$ \\
\hline
\end{tabular}

FIG. 11. (left) DJF BA event composite Hovmöller diagrams of mean dynamic tropopause meridional wind (8-kt contour interval; black solid: positive; black dashed: negative) and anomaly from DJF climatology (colored; 2-kt contour interval) computed for the (a) $50^{\circ}-80^{\circ}$ and (c) $20^{\circ}-50^{\circ} \mathrm{N}$ bands. Shaded anomalies are shown only when significant at the $90 \%$ level, computed using a two-sided Student's $t$ test. (right) Hovmöller diagrams of compositemean column-integrated baroclinic conversion $C_{A}$ (contoured every $4 \mathrm{~W} \mathrm{~m}^{-2}$; black solid: positive; black dashed: negative) and anomaly from DJF climatology (colored; $3 \mathrm{~W} \mathrm{~m}^{-2}$ contour interval), computed for the (b) $50^{\circ}-80^{\circ}$ and (d) $20^{\circ}-50^{\circ} \mathrm{N}$ bands.

In the midlatitudes, a series of coherent composite Rossby waves are noted in the BA event composite with eastward propagation of northerly and southerly wind anomalies with time (Fig. 11c). No significant downstream amplification of these anomalies is present through day -4 (Fig. 11c), wherein anomalies on the dynamic tropopause do not clearly act to enhance their downstream component (Orlanski and Chang 1993). A couplet of positive (negative) $C_{A}$ anomalies exceeding $5(-5) \mathrm{W} \mathrm{m}^{-2}$ is present from $180^{\circ}$ to $100^{\circ} \mathrm{W}$ from day -5 to day 1 (Figs. $11 \mathrm{c}, \mathrm{d}$ ). These $C_{A}$ anomalies are found to be associated with the anomalous southerly flow on the western flank (anomalous northerly flow on the eastern flank) of the North Pacific dynamic tropopause anticyclonic anomaly (Figs. 11c,d). Such regions are areas of implied anomalous cyclonic (anticyclonic) vorticity advection, which could result in ascent (descent). 
A. DT $\vec{v}$ : DJF BN, $50^{\circ}-80^{\circ} \mathrm{N}$

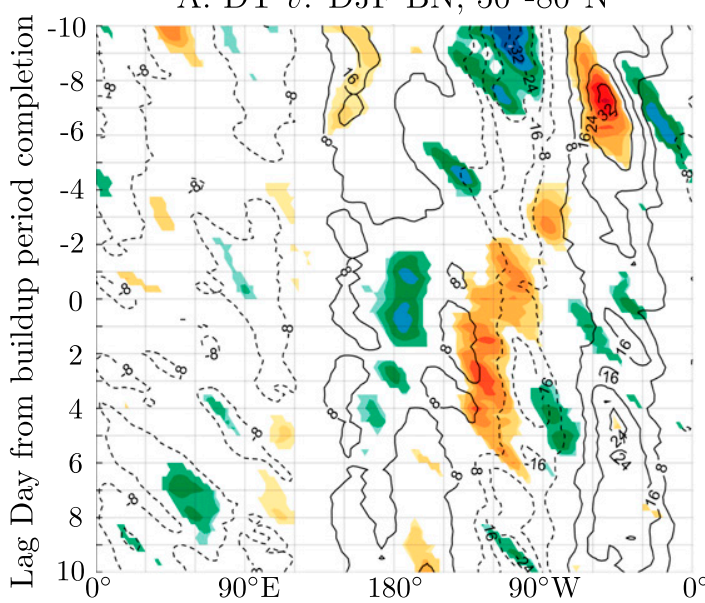

B. Column $\mathrm{C}_{A}$ : DJF BN, $50^{\circ}-80^{\circ} \mathrm{N}$

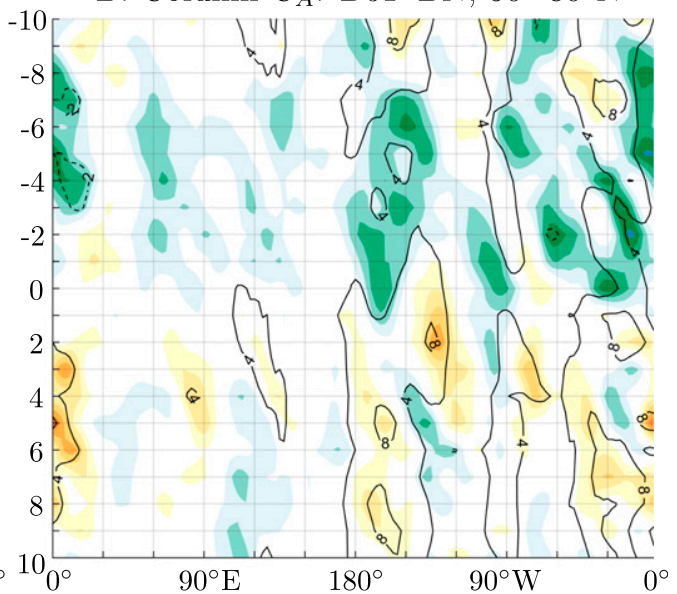

C. DT $\vec{v}$ : DJF BN, $20^{\circ}-50^{\circ} \mathrm{N}$

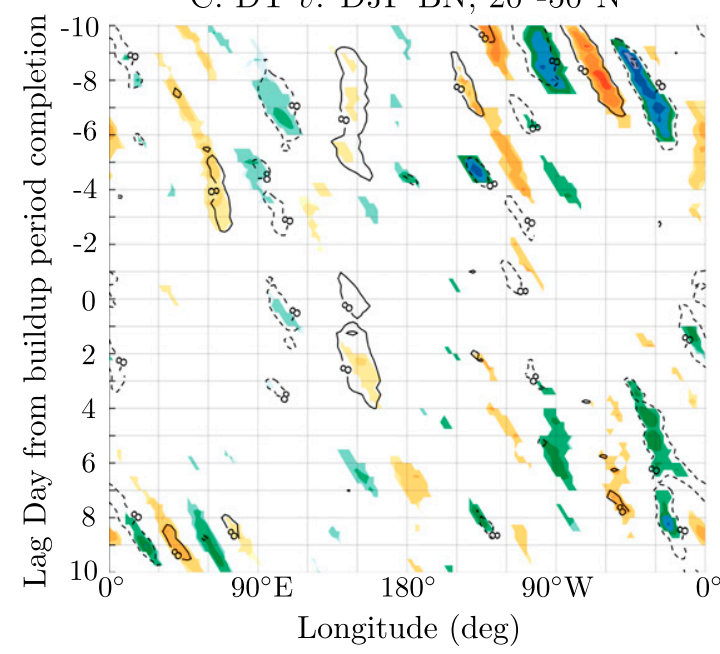

D. Column $\mathrm{C}_{A}$ : DJF BN, $20^{\circ}-50^{\circ} \mathrm{N}$
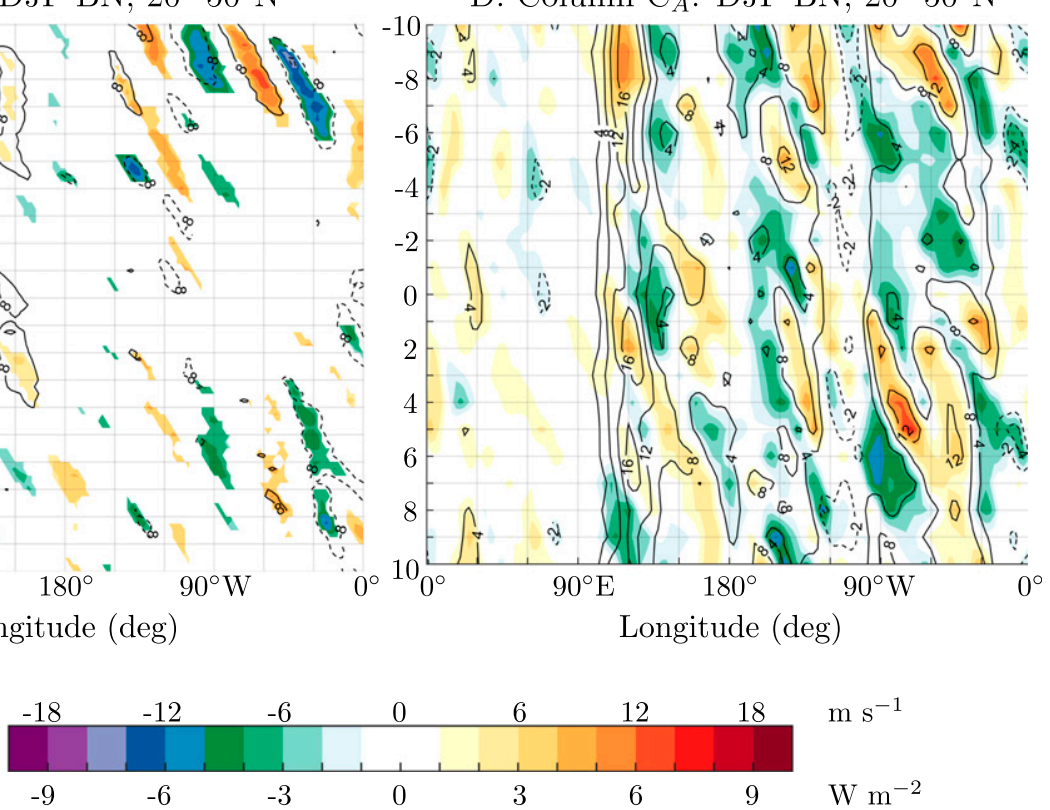

FIG. 12. As in Fig. 11, but for DJF BN event composite fields.

Other regions of anomalous northerly flow in the midlatitudes are also found to be associated with negative $C_{A}$ anomalies, resulting in a net negative anomaly for the latitudinal band. Near the end of the buildup event period (day -3), a coherent composite wave develops on day -3 near $120^{\circ} \mathrm{E}$ in response to the deepening trough associated with high-latitude cooling (Fig. 11c). This composite wave amplifies by day 0 near $180^{\circ}$ with anomalous northerlies in excess of $-12 \mathrm{kt}$ extending across both the mid- and high latitudes (Figs. 11a,c). The continued downstream propagation of the composite wave in the midlatitudes results in a downstream amplification that reaches Europe by day 4 (Fig. 11c). This coherent Rossby wave results in enhanced positive $C_{A}$ anomalies in the days following peak $A_{Z}$ (Fig. 11d) and is a likely mechanism responsible for concluding the buildup of $A_{Z}$.

The BN composite-mean dynamic tropopause field yields some notable differences from the BA composite. The coherent wave associated with the highly amplified flow over North America at the onset of the BN event period is noted for both the mid- and high-latitude meridional wind anomalies through day -6 (Figs. 12a,c). The apparent high-latitude retrogression of the ridge, as given by a westward propagation of anomalous northerly (southerly) flow from $110^{\circ}$ to $170^{\circ} \mathrm{W}$ (from $60^{\circ}$ to $110^{\circ} \mathrm{W}$ ), is less a retrogression of the composite-mean ridge and more a deamplification of the ridge over 
Alaska, followed by the establishment of a new trough by day -2 (Fig. 12a). However, the positive thickness anomaly and dynamic tropopause ridge do briefly retrogress through lag day -6 in response to southerly flow ahead of a trough over East Asia $\left(130^{\circ} \mathrm{E}\right.$; Fig. $\left.12 \mathrm{c}\right)$. Otherwise, the high-latitude composite Rossby wave field is similar to the BA event composite in that it lacks coherent anomalies and is generally associated with negative $C_{A}$ anomalies (Fig. 12b). In the midlatitudes, there is a broad lack of coherent composite Rossby wave features throughout the BN event period (Fig. 12c), and $C_{A}$ anomalies are generally weakly negative throughout the hemisphere (Fig. 12d). It is therefore reasonable to conclude from this result that the occurrence of robust Rossby waves during this period is below the climatological average.

\section{Discussion}

The role of synoptic-scale processes in modulating $A_{Z}$ manifests in anomalous contributions to $G_{Z}$ and $C_{A}$. The propagation of the warm anticyclonic anomaly across the eastern North Pacific basin plays an important role in establishing an environment capable of enhancing the regional baroclinic zone for the DJF BA event composite. The wind and thickness anomaly patterns in Figs. 8a$c$ are indicative of anticyclonic Rossby wave breaking on the dynamic tropopause. Such events are characterized by significant poleward (equatorward) filaments of high (low)-potential-temperature air that form in response to amplified Rossby waves embedded in an anticyclonically sheared background flow (e.g., Thorncroft et al. 1993). Further evidence of this feature is noted with a southwest-northeast-oriented stream of higher precipitable water values extending from the subtropics along the northwestern flank of a closed 700-hPa anticyclone by day -2 (Fig. 10b; closed anticyclone not shown). This pattern has previously been observed with anticyclonic wave breaking in this region (Payne and Magnusdottir 2014). Individual case analyses (not shown) indicate that these thickness and wind anomalies in the east Pacific are collocated with anticyclonic wave breaking for nearly all individual DJF BA events. Furthermore, Cordeira (2011) found increased $A_{Z}$ in the 12 days following North Pacific anticyclonic wave breaking events, in general agreement with our results.

Lower-tropospheric condensational heating beneath or slightly displaced to the equatorward side of the jet (Figs. 9a,b) is noted in association with the anticyclonic anomaly (Figs. 8a-c) and indicates a source of diabatic heating. Such diabatic heating on the equatorward side of the jet could contribute to anomalously high values of $G_{Z}$ for days -6 to 0 (Fig. 5a). Further subtropical heating with these events acts in part to increase the zonal extent of strong thermal gradients in the eastern Pacific basin, leading to an elongation of the North Pacific jet (Figs. 8a-c). The elongation of the jet will act to shift eastward the region of ascent and subsidence in association with the secondary circulations of the jet exit region. As a result, the eastern flank of the subtropical anticyclone in the equatorward exit region and the Gulf of Alaska cyclone in the poleward exit region is continually reinforced (Figs. 8b,c). This configuration also results in an eastward propagation of the surface systems, establishing a broad westerly flow across the eastern North Pacific. As such, this eastward propagation leads to a reduction in warm-air advection and poleward moisture flux into western and central Alaska for the latter portions of the BA composite event (Figs. 8b,c, 10b).

A similar pathway resulting in high-latitude cooling through diabatic processes is present for both the DJF $\mathrm{BA}$ and $\mathrm{BN}$ event composites. Poleward moisture flux is present in the early half of the period, which occurs due to the aforementioned wave breaking events for the BA event composite and due to ridging over Alaska in the BN event composite (Figs. 10a,c). This moisture flux occurs in a region of diagnosed ascent and warm-air advection, suggesting that precipitation is possible in this domain. Following the elongation of the jet for the BA event composite and the collapse of the ridge for the BN event composite, these high-latitude regions are generally isolated from notable temperature advections, moisture flux, or vertical motion, despite cooling in both instances. As such, it is reasonable to conclude that cooling in both events is driven by diabatic processes, which would act to contribute to the anomalously high values of $G_{Z}$ for days -6 to 0 (Figs. 5a,b).

Here, we propose a two-step process resulting in this diabatic cooling of northwestern North America, which is summarized schematically in Fig. 13. During the onset (early portion) of the composite $A_{Z}$ buildup event, areas of quasigeostrophic forcing for ascent due to warm-air advection occur in regions of moisture flux convergence, indicating that precipitation may be occurring (Figs. 13a,c). The most likely phase of any precipitation would be ice crystals in this region due to $1000-500-\mathrm{hPa}$ thickness values between 5100 and $5200 \mathrm{~m}$ (Figs. $8 \mathrm{a}-\mathrm{d}$ ). Near the completion of the $A_{Z}$ buildup period (Figs. 13b,d), the high latitudes are isolated through different synoptic processes. In the BA event composite, the high latitudes are isolated as the region of anticyclonic wave breaking propagates farther eastward through processes previously noted. For the BN event composite, the collapse of the ridge over northwestern North America toward a more zonal flow acts to suppress southerly flow into the region, acting to isolate the area from subtropical 

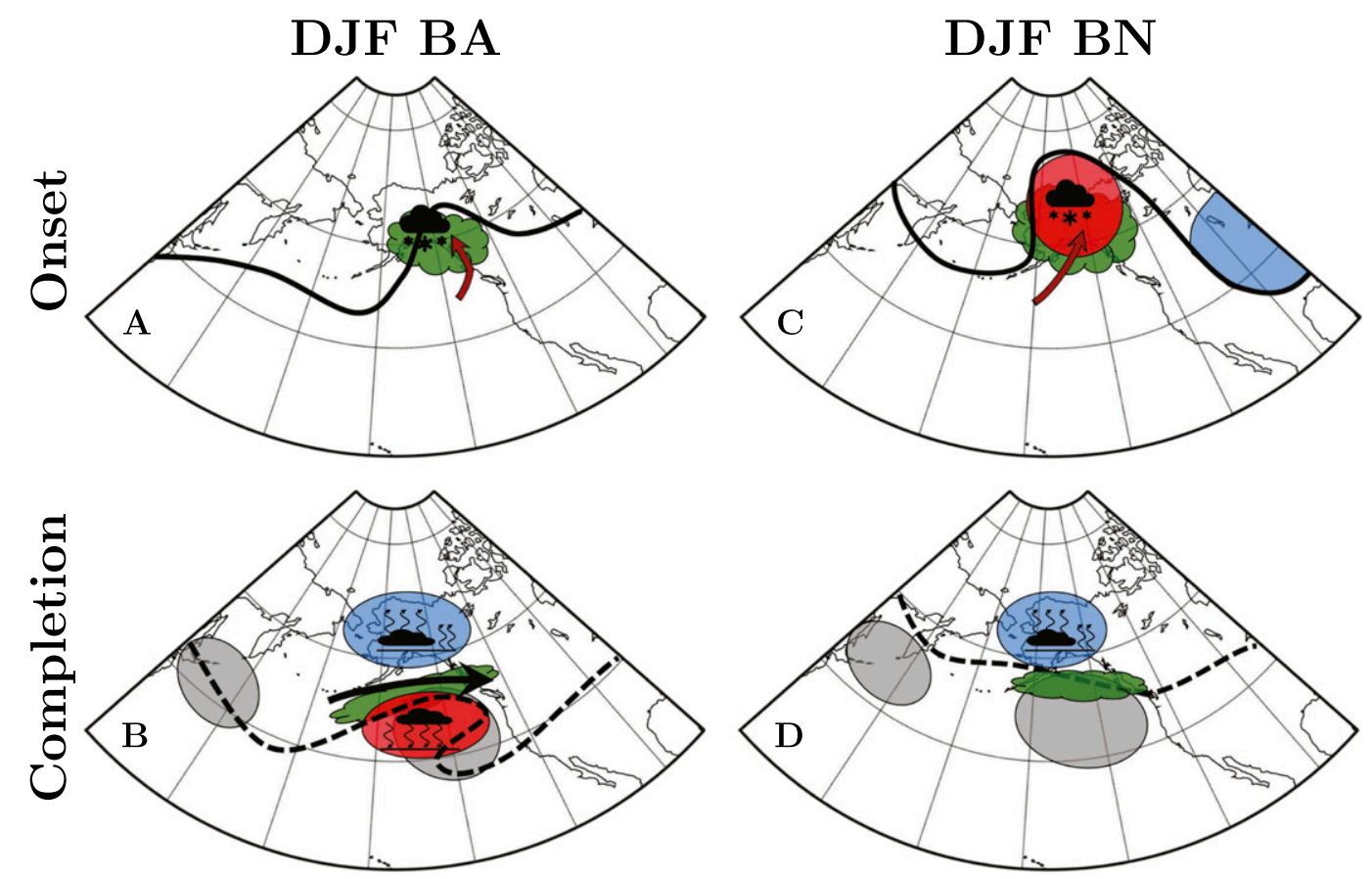

FIG. 13. Schematic diagram of processes contributing to (a),(b) BA and (c),(d) BN events from buildup event onset to completion. The solid (dashed) black line represents upper-tropospheric geopotential height contours at the start (end) of the event, thick black arrow represents the dynamic tropopause jet stream anomaly at the end of event, and red arrows represent warm-air advection. Red (blue) shaded regions represent positive (negative) 1000-500-hPa thickness anomalies, green clouds represent moisture flux convergence, and gray-shaded regions represent regions of reduced baroclinic conversion $C_{A}$. Periods of snowfall are represented by a cloud with snowfall, diabatic cooling through cloud and surface processes is represented by a cloud and upward small arrows, diabatic heating through condensational heating is represented by a cloud with downward small arrows, and surface downwelling radiation from clear sky is represented by isolated downward small arrows.

air masses. In both instances, we speculate this period of Arctic isolation results in diabatic cooling.

The cooling in this region is hypothesized to occur through previously noted Arctic airmass generation processes in the literature. Turner et al. (2013) demonstrated that diabatic cooling through radiation occurs in association with shallow clouds and ice crystal formation, along with sublimation and evaporation. These processes for rapid cooling events are similar to those for our event composites and could act to increase $G_{Z}$ in the high latitudes. Furthermore, Romanski and Rossow (2013) found that surface sensible heat flux from the atmosphere to the surface and radiative flux from low clouds are the two most effective sources of $G_{Z}$ in the winter Northern Hemisphere high latitudes. Our results suggest that similar processes are important here, wherein cooling is most significant either near the surface or just above a region of low clouds below $700 \mathrm{hPa}$ (Figs. 9b,d). We believe that such processes play an integral role in the development of anomalously high $G_{Z}$ in the period from day -6 to 0 for both the DJF BA and BN event composites.
Negative anomalies in midlatitude $C_{A}$ are found to be associated with northerly wind anomalies in the $20^{\circ}-$ $50^{\circ} \mathrm{N}$ region (Figs. $11 \mathrm{c}, \mathrm{d}, 12 \mathrm{c}, \mathrm{d}$ ). In particular, the flow reconfiguration associated with anticyclonic wave breaking results in a robust negative contribution toward $C_{A}$ downstream of the wave-breaking event (near $120^{\circ} \mathrm{W}$ ) for the DJF BA event composite (Figs. 11c,d). A further negative anomaly in $C_{A}$ is noted for the high latitudes $\left(50^{\circ}-85^{\circ} \mathrm{N}\right)$ with northerly wind anomaly upstream of the trough, which develops near $160^{\circ} \mathrm{E}-120^{\circ} \mathrm{W}$ for both the BA and BN event composites (Figs. 11, 12). It is evident for both $\mathrm{BA}$ and $\mathrm{BN}$ event composites that northerly wind anomalies are ubiquitously associated with negative $C_{A}$ anomalies. In many instances, these anomalous northerlies are associated with neutral to positive lower-tropospheric thickness anomalies, such as in the North Pacific during the period of anomalously low $C_{A}$ from day -6 to day 0 (Fig. 8). This particular juxtaposition of anomalies would result in either an anomalously low or negative contribution to the $v^{*} T^{*}$ term in Eq. (2). Implied anticyclonic vorticity advection in these regions would also result in negative 
contributions for the $\omega^{*} T^{*}$ term in Eq. (2). Furthermore, periods of incoherent composite-mean Rossby wave occurrences also are broadly associated with negative anomalies in $C_{A}$ (Figs. 12c,d). This result suggests that either incoherent or reduced frequencies of Rossby wave occurrences are also broadly associated with reductions in $C_{A}$ from the climatological mean (Figs. 13b,d).

\section{Conclusions and future work}

We have examined changes in zonal available potential energy $A_{Z}$ on synoptic time scales for the Northern Hemisphere. We computed $A_{Z}$ and its attendant generation $\left(G_{Z}\right)$ and conversion $\left(C_{Z}, C_{A}\right)$ terms in 6-h time intervals for the 1979-2011 period from the NCEP-DOE Reanalysis 2 dataset, resulting in a continuous 33-yr climatology of these energetics terms. Synoptic-scale variability was captured by applying a space-only analysis framework with a 3-day low-pass filter for the Northern Hemisphere domain $\left(20^{\circ}-85^{\circ} \mathrm{N}, 1000-100 \mathrm{hPa}\right)$. Events were categorized for all seasons as a function of their duration of $A_{Z}$ increase, magnitude of $A_{Z}$ change, and the peak $A_{Z}$ achieved by the end of a buildup event, resulting in the first climatology of synoptic-scale $A_{Z}$ buildup events. Buildups in $A_{Z}$ were achieved on synoptic time scales primarily through a reduction in $C_{A}$ and an increase in $G_{Z}$, though the latter two terms dominate the overall budget of $A_{Z}$. In general, $C_{A}$ decreased and $G_{Z}$ increased for the majority of composited buildup events, followed by a reversal of this signal just prior to peak $A_{Z}$ day, signifying the end of a buildup event.

A series of synoptic-scale processes was examined to determine their relative importance for perturbing $C_{A}$ and $G_{Z}$ for the winter season. Regional warming and cooling in the climatological exit region of the winter season North Pacific jet played the dominant role in generating $A_{Z}$ on synoptic time scales. A mechanism for diabatic cooling of the high latitudes was proposed, which could result in increased $G_{Z}$, while northerly or neutral anomalies in event composite winds were revealed to be associated with periods of anomalously low $C_{A}$. Winter buildup events to anomalously high $A_{Z}$ were found to be frequently associated with anticyclonic wave breaking in the eastern North Pacific basin. The $A_{Z}$ buildup events from an anomalously low state (buildup neutral) were broadly associated with a deamplification of a robust Western Hemisphere meridional flow into a more zonal pattern.

We have shown several pathways to increasing zonal available potential energy that do not necessitate a complete relaxation of the midlatitude flow to a zonally symmetric low-wavenumber state. Rossby wave breaking patterns appear to be an important process modulating winter $A_{Z}$, and the specific role of these patterns in modulating $A_{Z}$ provides an interesting area of future research. A further diagnosis of the synoptic patterns associated with $A_{Z}$ buildup events identified in other seasons may also lend insight into synoptic pathways toward a high energetic state. Finally, the importance of these buildup events for ensuing $A_{Z}$ depletion events is also an interesting area of future research. An exploration of the role of such buildup events for the medium-range predictability of high-impact cyclones and blocking events would be an appropriate application of this work.

The climatology of $A_{\mathrm{ZA}}$ also demonstrated several subseasonal to seasonal oscillation periods of interest for future studies. Notable subseasonal buildups in $A_{\mathrm{ZA}}$ that exceeded synoptic time scales were observed (e.g., October-November 1980, March-April 1982, and September-October 1995). Furthermore, several distinct clusterings of three to four synoptic-time-scale buildup events were observed within a 60-90-day period (e.g., November 1983-January 1984, SeptemberDecember 1984, March-April 2000, and September 2008-March 2009). Such periods have been previously examined in autumn months (Cordeira 2011) and were associated with notable tropical teleconnection patterns. Though our study examined the synoptic-scale processes resulting in changes to $A_{Z}$ during a buildup event, it would be of interest to examine the synoptic-, subseasonal-, and seasonal-scale mechanisms that may precede such buildup periods in the first place.

Acknowledgments. This research has been supported by the Natural Sciences and Engineering Research Council (Discovery Grant and Climate Change and Atmospheric Research Grant for the Canadian Network for Regional Climate and Weather Processes). The authors thank Dr. Jason Cordeira and the remaining anonymous reviewers for their insightful commentary, which has greatly improved the manuscript.

\section{REFERENCES}

Black, M. T., and A. B. Pezza, 2013: A universal, broad-environment energy conversion signature of explosive cyclones. Geophys. Res. Lett., 40, 452-457, https://doi.org/10.1002/grl.50114.

Boer, G. J., 1982: Diagnostic equations in isobaric coordinates. Mon. Wea. Rev., 110, 1801-1820, https://doi.org/10.1175/ 1520-0493(1982)110<1801:DEIIC > 2.0.CO;2.

Bosart, L. F., G. J. Hakim, K. R. Tyle, M. A. Bedrick, W. E. Bracken, M. J. Dickinson, and D. M. Schultz, 1996: Largescale antecedent conditions associated with the 12-14 March 1993 cyclone ("Superstorm '93") over eastern North America. Mon. Wea. Rev., 124, 1865-1891, https://doi.org/10.1175/ 1520-0493(1996)124<1865:LSACAW>2.0.CO;2.

Brown, J. A., Jr., 1964: A diagnostic study of tropospheric diabatic heating and the generation of available potential energy. Tellus, 16, 371-388, https://doi.org/10.3402/tellusa.v16i3.8931. 
Chen, T.-C., 1982: A further study of spectral energetics in the winter atmosphere. Mon. Wea. Rev., 110, 947-961, https:// doi.org/10.1175/1520-0493(1982)110<0947:AFSOSE>2.0.CO;2.

Clapp, P. F., 1961: Normal heat sources and sinks in the lower troposphere in winter. Mon. Wea. Rev., 89, 147-162, https:// doi.org/10.1175/1520-0493(1961)089<0147:NHSASI >2.0.CO;2.

Cordeira, J. M., 2011: Tropical-extratropical interactions and arctic-extratropical interactions conducive to intraseasonal variability of the North Pacific jet stream. Ph.D. dissertation, University at Albany, State University of New York, 202 pp.

Duck Min, K., and L. H. Horn, 1982: Available potential energy in the Northern Hemisphere during the FGGE year. Tellus, 34, 526-539, https://doi.org/10.3402/tellusa.v34i6.10838.

Dutton, J. A., and D. R. Johnson, 1967: The theory of available potential energy and a variational approach to atmospheric energetics. Advances in Geophysics, Vol. 12, Academic Press, 333-436, https://doi.org/10.1016/S0065-2687(08)60379-9.

Garreaud, R. D., 2001: Subtropical cold surges: Regional aspects and global distribution. Int. J. Climatol., 21, 1181-1197, https:// doi.org/10.1002/joc.687.

Grumm, R. H., and R. Hart, 2001: Standardized anomalies applied to significant cold season weather events: Preliminary findings. Wea. Forecasting, 16, 736-754, https://doi.org/10.1175/ 1520-0434(2001)016<0736:SAATSC $>2.0$. CO;2.

Gyakum, J. R., 2008: The application of Fred Sanders' teaching to current research on extreme cold-season precipitation events in the Saint Lawrence River valley region. Synoptic-Dynamic Meteorology and Weather Analysis Forecasting: A Tribute to Fred Sanders, Meteor. Monogr., No. 55, Amer. Meteor. Soc., 241-250, https://doi.org/10.1175/0065-9401-33.55.241.

Hansen, A. R., and R. L. Nagle, 1984: Estimates of the generation of available potential energy by infrared radiation. Mon. Wea. Rev., 112, 1370-1377, https://doi.org/10.1175/1520-0493(1984) $112<1370$ :EOTGOA $>2.0$. CO;2.

Johnson, D. R., 1967: The role of terrestrial radiation in the generation of zonal and eddy available potential energy. Tellus, 19, 517-539, https://doi.org/10.1111/j.2153-3490.1967. tb01506.x.

_ 1970: The available potential energy of storms. J. Atmos. Sci., 27, 727-741, https://doi.org/10.1175/1520-0469(1970)027<0727: TAPEOS $>2.0 . \mathrm{CO} ; 2$.

Kanamitsu, M., W. Ebisuzaki, J. Woollen, S.-K. Yang, J. J. Hnilo, M. Fiorino, and G. L. Potter, 2002: NCEP-DOE AMIP-II Reanalysis (R-2). Bull. Amer. Meteor. Soc., 83, 1631-1643, https://doi.org/10.1175/BAMS-83-11-1631.

Krueger, A. F., J. S. Winston, and D. A. Haines, 1965: Computations of atmospheric energy and its transformation for the Northern Hemisphere for a recent five-year period. Mon. Wea. Rev., 93, 227-238, https://doi.org/10.1175/1520-0493 (1965)093<0227:COAEAI >2.3.CO;2.

Lau, N.-C., and K.-M. Lau, 1984: The structure and energetics of midlatitude disturbances accompanying cold-air outbreaks over East Asia. Mon. Wea. Rev., 112, 1309-1327, https:// doi.org/10.1175/1520-0493(1984)112<1309:TSAEOM>2.0.CO;2.

Lin, S. C., and P. J. Smith, 1979: Diabatic heating and generation of available potential energy in a tornado-producing extratropical cyclone. Mon. Wea. Rev., 107, 1169-1183, https:// doi.org/10.1175/1520-0493(1979)107<1169:DHAGOA > 2.0.CO;2.

Lorenz, E. N., 1955: Available potential energy and the maintenance of the general circulation. Tellus, 7, 157-167, https:// doi.org/10.3402/tellusa.v7i2.8796.

- 1960: Energy and numerical weather prediction. Tellus, $\mathbf{1 2}$ 364-373, https://doi.org/10.3402/tellusa.v12i4.9420.
Marques, C. A. F., A. Rocha, J. Corte-Real, J. M. Castanheira, J. Ferreira, and P. Melo-Gonçalves, 2009: Global atmospheric energetics from NCEP-reanalysis 2 and ECMWF-ERA40 reanalysis. Int. J. Climatol., 29, 159-174, https://doi.org/ 10.1002/joc.1704.

Muench, H. S., 1965: On the dynamics of the wintertime stratosphere circulation. J. Atmos. Sci., 22, 349-360, https://doi.org/ 10.1175/1520-0469(1965)022<0349:OTDOTW>2.0.CO;2.

O'Gorman, P. A., 2010: Understanding the varied response of the extratropical storm tracks to climate change. Proc. Natl. Acad. Sci. USA, 107, 19176-19180, https://doi.org/10.1073/pnas.1011547107.

Oort, A. H., 1964: On estimates of the atmospheric energy cycle. Mon. Wea. Rev., 92, 483-493, https://doi.org/10.1175/ 1520-0493(1964)092<0483:OEOTAE $>2.3$.CO;2.

— the atmosphere on a planetary scale. J. Geophys. Res., 79, 2705-2719, https://doi.org/10.1029/JC079i018p02705.

- and - 1976: On the variability of the atmospheric energy cycle within a 5-year period. J. Geophys. Res., 81, 3643-3659, https://doi.org/10.1029/JC081i021p03643.

Orlanski, I., and E. K. M. Chang, 1993: Ageostrophic geopotential fluxes in downstream and upstream development of baroclinic waves. J. Atmos. Sci., 50, 212-225, https://doi.org/10.1175/ 1520-0469(1993)050<0212:AGFIDA > 2.0.CO;2.

Payne, A. E., and G. Magnusdottir, 2014: Dynamics of landfalling atmospheric rivers over the North Pacific in 30 years of MERRA reanalysis. J. Climate, 27, 7133-7150, https://doi.org/ 10.1175/JCLI-D-14-00034.1.

Peixóto, J. P., and A. H. Oort, 1974: The annual distribution of atmospheric energy on a planetary scale. J. Geophys. Res., 79, 2149-2159, https://doi.org/10.1029/JC079i015p02149.

Pezza, A. B., J. A. P. Veiga, I. Simmonds, K. Keay, and M. dos Santos Mesquita, 2010: Environmental energetics of an exceptional high-latitude storm. Atmos. Sci. Lett., 11, 39-45, https://doi.org/10.1002/asl.253.

Romanski, J., and W. B. Rossow, 2013: Contributions of individual atmospheric diabatic heating processes to the generation of available potential energy. J. Climate, 26, 4244-4263, https:// doi.org/10.1175/JCLI-D-12-00457.1.

Smith, P. J., and P. M. Dare, 1986: The kinetic and available potential energy budget of a winter extratropical cyclone system. Tellus, 38A, 49-59, https://doi.org/10.3402/tellusa.v38i1.11697.

Thorncroft, C. D., B. J. Hoskins, and M. E. McIntyre, 1993: Two paradigms of baroclinic-wave life-cycle behavior. Quart. J. Roy. Meteor. Soc., 119, 17-55, https://doi.org/10.1002/qj.49711950903.

Turner, J. K., J. Gyakum, and S. M. Milrad, 2013: A thermodynamic analysis of an intense North American arctic air mass. Mon. Wea. Rev., 141, 166-181, https://doi.org/10.1175/MWR-D-12-00176.1.

Veiga, J. A. P., A. B. Pezza, I. Simmonds, and P. L. Silva Dias, 2008: An analysis of the environmental energetics associated with the transition of the first South Atlantic hurricane. Geophys. Res. Lett., 35, L15806, https://doi.org/10.1029/2008GL034511.

Wiin-Nielsen, A., and J. Brown, 1962: On diagnostic computations of atmospheric heat sources and sinks and the generation of available potential energy. Proc. Int. Symp. Numerical Weather Prediction, Tokyo, Japan, Meteorological Society of Japan, 593-613.

Winston, J. S., and A. F. Krueger, 1961: Some aspects of a cycle of available potential energy. Mon. Wea. Rev., 89, 307-318, https://doi.org/10.1175/1520-0493-89.9.307.

Wintels, W., and J. R. Gyakum, 2000: Synoptic climatology of Northern Hemisphere available potential energy collapses. Tellus, 52A, 347-364, https://doi.org/10.3402/tellusa.v52i4.12273. 